The University of San Francisco

USF Scholarship: a digital repository @ Gleeson Library |

Geschke Center

Kinesiology (Formerly Exercise and Sport Science)

College of Arts and Sciences

2007

\title{
Variable Ticket Pricing in Major League Baseball
}

Daniel A. Rascher

University of San Francisco, RASCHER@USFCA.EDU

Chad D. McEvoy

Mark S. Nagel

Matthew T. Brown

Follow this and additional works at: http://repository.usfca.edu/ess

Part of the Sports Management Commons

\section{Recommended Citation}

Rascher, Daniel A.; McEvoy, Chad D.; Nagel, Mark S.; and Brown, Matthew T., "Variable Ticket Pricing in Major League Baseball" (2007). Kinesiology (Formerly Exercise and Sport Science). Paper 6.

http://repository.usfca.edu/ess/6

This Article is brought to you for free and open access by the College of Arts and Sciences at USF Scholarship: a digital repository @ Gleeson Library | Geschke Center. It has been accepted for inclusion in Kinesiology (Formerly Exercise and Sport Science) by an authorized administrator of USF Scholarship: a digital repository@ Gleeson Library | Geschke Center. For more information, please contact repository@usfca.edu. 


\title{
ECONOMICS AND FINANCE
}

Journal of Sport Management, 2007, 21, 407-437

(c) 2007 Human Kinetics, Inc.

\section{Variable Ticket Pricing in Major League Baseball}

\author{
Daniel A. Rascher \\ University of San Francisco
}

\author{
Chad D. McEvoy \\ Illinois State University
}

\section{Mark S. Nagel and Matthew T. Brown \\ University of South Carolina}

\begin{abstract}
Sport teams historically have been reluctant to change ticket prices during the season. Recently, however, numerous sport organizations have implemented variable ticket pricing in an effort to maximize revenues. In Major League Baseball variable pricing results in ticket price increases or decreases depending on factors such as quality of the opponent, day of the week, month of the year, and for special events such as opening day, Memorial Day, and Independence Day. Using censored regression and elasticity analysis, this article demonstrates that variable pricing would have yielded approximately $\$ 590,000$ per year in additional ticket revenue for each major league team in 1996, ceteris paribus. Accounting for capacity constraints, this amounts to only about a $2.8 \%$ increase above what occurs when prices are not varied. For the 1996 season, the largest revenue gain would have been the Cleveland Indians, who would have generated an extra \$1.4 million in revenue. The largest percentage revenue gain would have been the San Francisco Giants. The Giants would have seen an estimated $6.7 \%$ increase in revenue had they used optimal variable pricing.
\end{abstract}

Variable ticket pricing (VTP) has recently been a much-discussed topic in the business of sport, especially as it relates to professional baseball, professional hockey, and college football (King, 2003; Rovell, 2002a). VTP refers to changing the price of a sporting-event ticket based on the expected demand for that event. For example, Major League Baseball's (MLB) Colorado Rockies had four different price levels for the same seat throughout the season (Cameron, 2002). The different price levels were based primarily on the time of the year (summer versus spring or fall), day of the week (weekends versus weekdays), holidays (Memorial Day, Independence Day, etc.), the quality of the Rockies' opponent, or their opponents' star players (e.g., Barry Bonds). The same seat in the outfield pavilion section of Coors Field, the Rockies' home stadium, ranged in price in 2004 from a high of

Rascher is with the Sport Management Program, University of San Francisco, San Francisco, CA 94117. McEvoy is with the School of Kinesiology and Recreation, Illinois State University, Normal, IL 61790. Nagel and Brown are with the Dept. of Sport and Entertainment Management, University of South Carolina, Columbia, SC 29208. 
\$21 for what the Rockies labeled as "marquee" games to a low of \$11 for what were considered "value" games. MLB teams who used VTP in 2004 are detailed in Table 1. Other sport organizations besides MLB franchises use VTP, as well. Several National Hockey League (NHL) teams use VTP strategies, as do a number of intercollegiate athletics programs (Rooney, 2003; Rovell, 2002a).

Some MLB teams have concluded that their 81 home games are not 81 units of the same product, but rather, based on the aforementioned characteristics such as the day of the week and quality of the opponent, are 81 unique products. As such, the 81 unique products should each be priced according to their own characteristics that make them more or less attractive to the potential consumer. MLB attendance studies support this notion. For example, in a study including more than 50 independent variables in explaining MLB game attendance, McDonald and Rascher (2000) found variables such as day of the week, home and visiting teams' winning percentages, and weather, among many others, to be statistically significant predictors of game attendance. Clearly, a variety of factors make some games more appealing and others less appealing to consumers. It seems quite logical to price tickets to these games at different levels, especially with teams constantly searching for revenue sources to compete with their opponents for players (Howard \& Crompton, 2004; Zimbalist, 2003).

The varying quality of games throughout a season often creates a secondary market because demand for the most popular games might exceed available supply. Independent ticket agents, or scalpers, broker tickets obtained from various sources to fans unable or unwilling to purchase tickets from a team's ticket office or licensed ticket agency (Caple 2001; Reese, 2004). Ticket scalpers respond to market demands (often in violation of city ordinances or state laws), but the team initially selling the ticket does not realize any increased revenue during a scalper's transaction ("History of Ticket Scalping," n.d.). For this reason, the Chicago Cubs have recently permitted ticket holders to auction their Wrigley Field tickets on a

Table 12004 MLB Variable Ticket Pricing Programs

\begin{tabular}{lcl}
\hline & $\begin{array}{c}\text { Number } \\
\text { of } \\
\text { Levels }\end{array}$ & Levels (price for typical outfield bleacher seats) \\
\hline Arizona Diamondbacks & 3 & premier $(\$ 18)$, weekend $(\$ 15)$, weekday $(\$ 13)$ \\
Atlanta Braves & 2 & premium $(\$ 21)$, regular $(\$ 18)$ \\
Chicago Cubs & 3 & prime $(\$ 35)$, regular $(\$ 26)$, value $(\$ 15)$ \\
Chicago White Sox & 2 & weekend $(\$ 26)$, weekday $(\$ 22)$ \\
Colorado Rockies & 4 & marquee $(\$ 21)$, classic $(\$ 19)$, premium $(\$ 17)$, value $(\$ 11)$ \\
New York Mets & 4 & gold $(\$ 16)$, silver $(\$ 14)$, bronze $(\$ 12)$, value $(\$ 5)$ \\
San Francisco Giants & 2 & Friday-Sunday $(\$ 21)$, Monday-Thursday $(\$ 16)$ \\
Tampa Bay Devil Rays & 3 & prime $(\$ 20)$, regular $(\$ 17)$, value $(\$ 10)$ \\
Toronto Blue Jays & 3 & premium $(\$ 26)$, regular $(\$ 23)$, value $(\$ 15)$ \\
\hline
\end{tabular}

Note. Different seating configurations of each stadium make comparing like seats difficult; however, this attempt was made to provide the reader with an idea of the range of price levels used by each team for similar seats. Source: www.mlb.com. 
Cubs affiliated Web site, with a fee being paid to the Cubs for this service (Rovell, 2002b; see also www.buycubstickets.com). It is believed that instituting a comprehensive VTP policy would diminish the influence of scalpers and permit greater revenue to be generated by the team for games in high demand.

Many industries have previously embraced the variable pricing concept as a method for increasing revenue and providing more efficient service to consumers (Bruel, 2003; Rovell, 2002a). Airline flights are typically more expensive for selected days of the week (Monday, Friday), times of the day (morning, late afternoon), and days of the year (holidays) when travel demand is higher. The airlines also use variable pricing to encourage passengers to book their flights early (typically a purchase at least 10-14 days in advance results in a lower fare) or, in some cases, at the last minute ("Travel Tips," 2004). Hotel pricing characteristically reflects expected demand, even though the actual physical product does not change, because rooms for weekends or holidays are usually priced higher than for weekdays or off-season visits. In fact, sometimes variable pricing even relates to major sporting events like the Super Bowl. Many hotels substantially raise room rates during Super Bowl week (Baade \& Matheson, n.d.). Other industries such as transportation use variable pricing; some toll roads now charge higher toll rates during peak times and lower rates during off-peak times ("Group Commends," 2001). The arts use variable pricing; matinee movie pricing is one example (Riley, 2002).

Sports franchises are moving forward with VTP strategies before sufficient research has been done to empirically evaluate its specific merits to the industry. This article provides a straightforward assessment of optimal VTP. First, a review of the literature reveals difficulties in estimating the nature of demand functions in sports. Specifically, optimal pricing is partially determined by price elasticities of demand, yet it is difficult to estimate ticket-price elasticities that are consistent over time. Next, a theory of complementary demand is explained that will account for nonticket products and services and the effect that ticket prices have on the demand for these products and services. Then, using individual game data from the 1996 MLB season, ticket prices and corresponding quantities are estimated that would have maximized ticket revenue. These are compared with actual prices and revenue to determine the yield from initiating a VTP policy. The final section contains a discussion of the implications of the results. In summary, this article shows that there are financial benefits to be gained from implementing VTP, details how much can be gained from a general VTP policy, and provides strategies for implementing VTP.

\section{Review of Literature}

\section{Price Elasticity of Demand in Sports}

Although the literature specifically investigating VTP in sport is limited, the literature on estimating demand functions and the corresponding elasticities for sporting events is extensive. It is typical for these studies to estimate the price elasticity of demand to see whether sports teams are setting price to maximize revenue (or profit if it can be shown that variable costs are relatively negligible). In practice, one could adjust season ticket prices and institute a VTP policy that increases revenue based on the results of elasticity studies. One problem is that the results 
are not consistent across studies. One explanation for this is that it is reasonable for prices to be set in the elastic, inelastic, or unit elastic portion of demand under various circumstances. For instance, profit maximization results in prices that are in the elastic portion of demand if marginal costs are above zero. If marginal costs are not above zero, then optimal prices are such that profit maximization equals revenue maximization, which occurs at unit elasticity. If other revenue streams are accounted for, such as concessions or parking, however, then optimal pricing can be in the inelastic portion of demand. Thus, each of these three demand-elasticity pricing strategies is justifiable. It is generally assumed in sports ticket pricing that the marginal cost of selling an extra seat is so low that the elastic part of demand is not optimal in terms of pricing. Any price from unit elasticity down into the inelastic portion of demand is a likely finding, as shown in the literature.

Noll's (1974) point estimates for elasticity for baseball were -0.49 for the 1970 and 1971 seasons. For the 1984 MLB season, Scully (1989) estimated point elasticities of -0.63 and -0.76 . Boyd and Boyd (1996) used Scully's 1984 data but added a measure of competition (recreational index for each city) and used a recursive feedback loop that incorporated the effects of home-field advantage. Namely, not only do more wins increase attendance, but enhanced attendance increases the likelihood of winning because a greater home-field advantage is created. In this study, point elasticities ranged from -0.58 to -1.20 . Hence, Boyd and Boyd discovered elasticities that were in the expected range, near or above unit elasticity. It is important to note that economists have a habit of referring to price elasticities as being positive even though they are actually negative. A price elasticity of -1.5 is in the expected range for a profit-maximizing decision maker. In fact, any price elasticity that is -1.0 or lower (meaning -1.5 or -2.0 ) is consistent with profit maximization. A price elasticity of -2.0 , however, will often be called a higher elasticity than -0.8 , referring to the absolute value of elasticity and ignoring the sign (which is always negative).

Scully's (1984), Noll's (1974), and Boyd and Boyd's (1996) estimates all had large enough confidence intervals on the ticket-price coefficient to not exclude unit elasticity as a possibility. In other words, none of those studies could reject the hypothesis that teams set ticket prices to maximize revenue. A study by Whitney (1988) that used more observations than those previously discussed, however, did yield an estimate of price elasticity that fell within the inelastic portion of demand. Furthermore, Marburger (1997) found price elasticities in the inelastic part of demand using annual team-level data covering a 20 -year period. The implications of inelastic pricing will be explained in the Theoretical Foundations section.

Fort (2004) recently summarized the literature on spectator-sports demand analysis and the difficulty in measuring price elasticities. He noted that simply analyzing one revenue stream makes it appear that pricing is not profit maximizing and that a more complete accounting of all revenue streams (e.g., tickets, concessions, and local television) is consistent with profit-maximization pricing. Given this discussion of price elasticities and profit maximization, the current study incorporates models that attempt to include the relationship between ticket and concession prices. 


\section{Ticket Pricing Issues}

It has been difficult for researchers to show profit-maximizing ticket pricing by sports teams. There are a number of reasons for this besides the inclusion of other revenue streams. First, most pricing data is a simple average of prices that are available for various seats for each team each season. Currently, Team Marketing Report (TMR) collects pricing data that some researchers have used (e.g., Rishe \& Mondello, 2004; Rascher, 1999). Although it is likely an improvement over previously collected pricing data, it has lacked consistency across teams and over time. Numerous discussions by the authors and TMR have revealed that TMR is able to separate out the luxury-suite ticket prices. TMR has also separated out club-seating prices for some, but not all, teams. Furthermore, this varies across seasons. TMR relies on the teams to self-report. Because of the prominence of the TMR Fan Cost Index, some teams potentially manipulate their reported prices to appear relatively inexpensive. Moreover, the number of seats available at each price level does not typically weight these prices. In addition, the number of seats sold is generally known in aggregate, not separated by seat price. Second, Demmert (1973) noted that there is a correlation between population and ticket price across many seasons (likely based on the connection to income in which more highly populated areas are associated with higher incomes, increasing demand and, therefore, prices). This multicollinearity can cloud the interpretation of coefficients on price. Third, as Salant (1992) pointed out, the long-term price of tickets might be optimal (adjusting for risk), but in the short term a team might be over- or underpricing in order to maintain consistency. This is a form of insurance in which the team bears the risk. Fourth, similar to Fort's (2004) findings, ticket prices might be kept relatively low in order to increase the number of attendees at an event who are likely to spend more money on parking, concessions, and merchandise and who will drive up sponsorship revenue for the team, thus maximizing overall revenues, rather than simply ticket revenues.

DeSerpa (1994) discussed the rationality of apparently low season-ticket prices. Even though many games sell out in the National Basketball Association and National Football League (focal sports in his study), it is rational for the seller to price below the myopic short-term demand price in order to give a fan a reason to purchase season tickets. In fact, DeSerpa discussed the possibility, but unlikeliness, of charging different prices for each event based on its demand. He surmised that it was administratively expensive and subject to potential negative fan reaction.

DeSerpa (1994) also noted that it is optimal to underprice season tickets if fans will likely want to attend only some of the games and resell the tickets for the remaining contests. The season ticket must be priced low enough for holders to be able to at least recoup their initial investment after assuming the transaction costs of resale (e.g., time, effort, search costs, and actual costs such as postage and advertising). Lower priced season tickets also potentially created a homefield advantage for teams. Each argument or concern DeSerpa proffered can be addressed in a VTP system. 
Marburger (1997) developed a model showing that pricing on the inelastic portion of demand can be explained by accounting for nonticket purchases such as concessions. Marburger noted that baseball teams set prices on the inelastic portion of demand, but he did not investigate whether pricing was based on concessions decisions, just that it occurs. Under multiple methods of measuring ticket price, Coates and Harrison (2005) found that ticket demand is also quite price inelastic.

\section{Variable Pricing Literature}

Specific to variable pricing, Heilman and Wendling (1976) analyzed ticket-price discounting by the Milwaukee Bucks of the National Basketball Association. The Bucks discounted prices from $\$ 5$ to $\$ 2$ and from $\$ 3.50$ to $\$ 2$ for 15 games of the 1974-75 season. The fifteen 1973-74 games that corresponded to the 1974-75 discounted games averaged 9,307 fans and had only three sellouts. The discounted 1974-75 games averaged 10,396 fans and had nine sellouts. Certainly, several factors (winter weather, player injuries, or even reversion to the mean) beyond the discounted price could have contributed to the attendance increases. Other teams did not duplicate the Bucks' attempt to discount tickets, however. Although the increase in attendance might appear minimal and result from other factors besides discounting, when ancillary revenue sources (parking, concessions, and merchandise sales) are added to the cost of a ticket, further investigation into VTP was warranted. The Bucks, however, remained one of the few teams in American professional sport to implement a form of VTP until 1999 (King, 2002a; Rovell, 2002b).

Although some research has been conducted regarding VTP, this limited body of knowledge is not yet sufficient to provide evidence concerning the merits of using VTP to set single-game ticket prices for sporting events. Despite this lack of information, some teams have implemented variable pricing, but others have remained skeptical (King, 2002a). This study investigates the financial gains of VTP and provides some direction regarding how it should be implemented in MLB.

\section{Theoretical Foundations}

The demand for baseball games changes from game to game, partly because of the varying quality and perception of quality of the home and visiting teams and partly because of nonperformance factors such as day of the week or month. For a given price, Table 2 (columns 2 and 3 ) shows that attendance varies greatly across games. The average deviation from the mean is nearly $23 \%$. For 11 of the Atlanta Braves' 81 home games, the deviation from the mean is over 30\%, and the Braves are not even in the top half of teams with high attendance variation.

In general, many organizations are trying to minimize the effect of team performance, which is one of the key factors in the changing demand from game to game (Brockinton, 2003; George, 2003). As shown in the literature, team performance is one of the most significant demand factors that can be affected by an owner. For example, Bruggink and Eaton (1996) and Rascher (1999) analyzed game-by-game attendance and the importance of team performance. Using annual data, Alexander (2001) showed that the variable with the highest statistical significance is the number of games behind the leader, a measure of team performance. Teams are building new stadiums, improving concessions and restaurants, and creating areas 


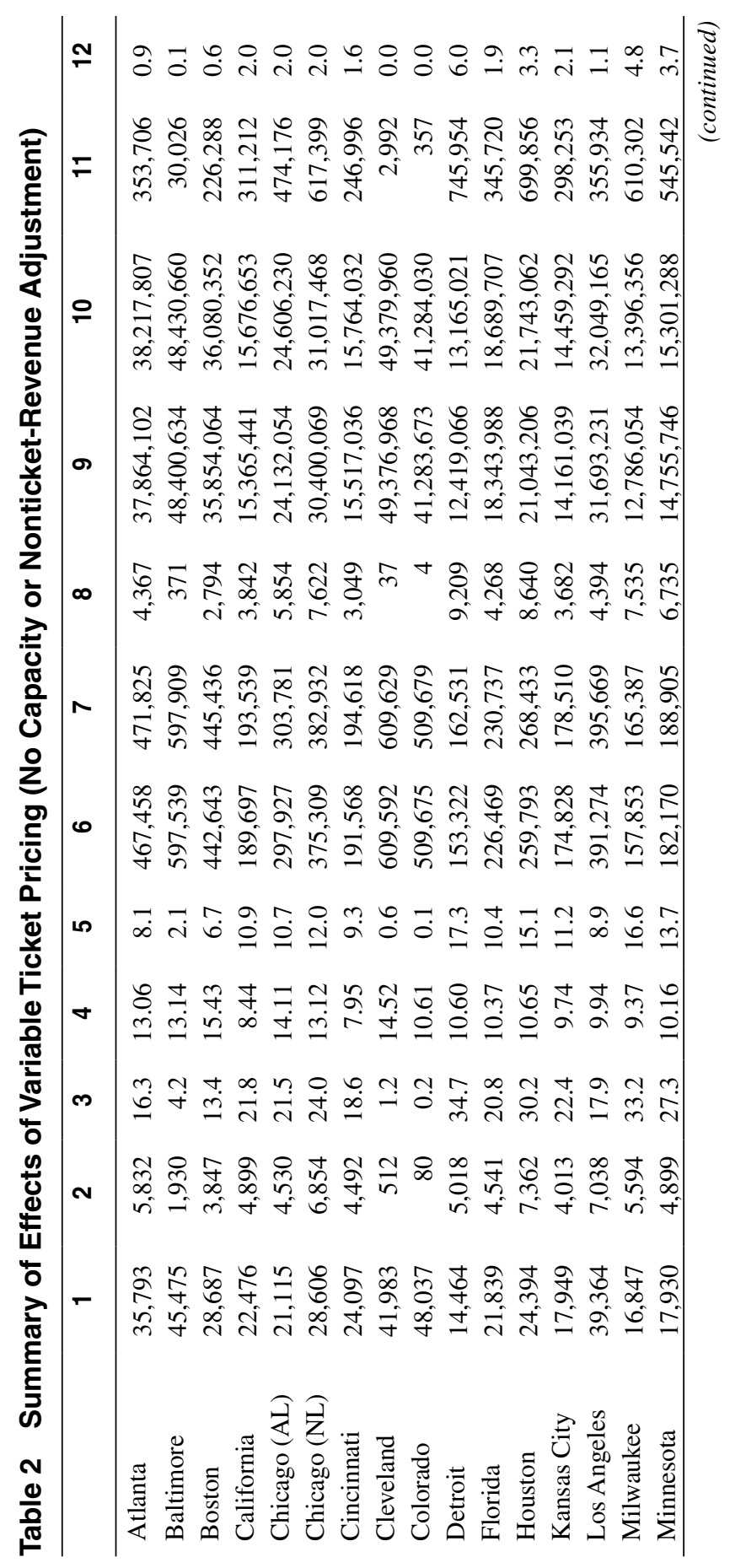




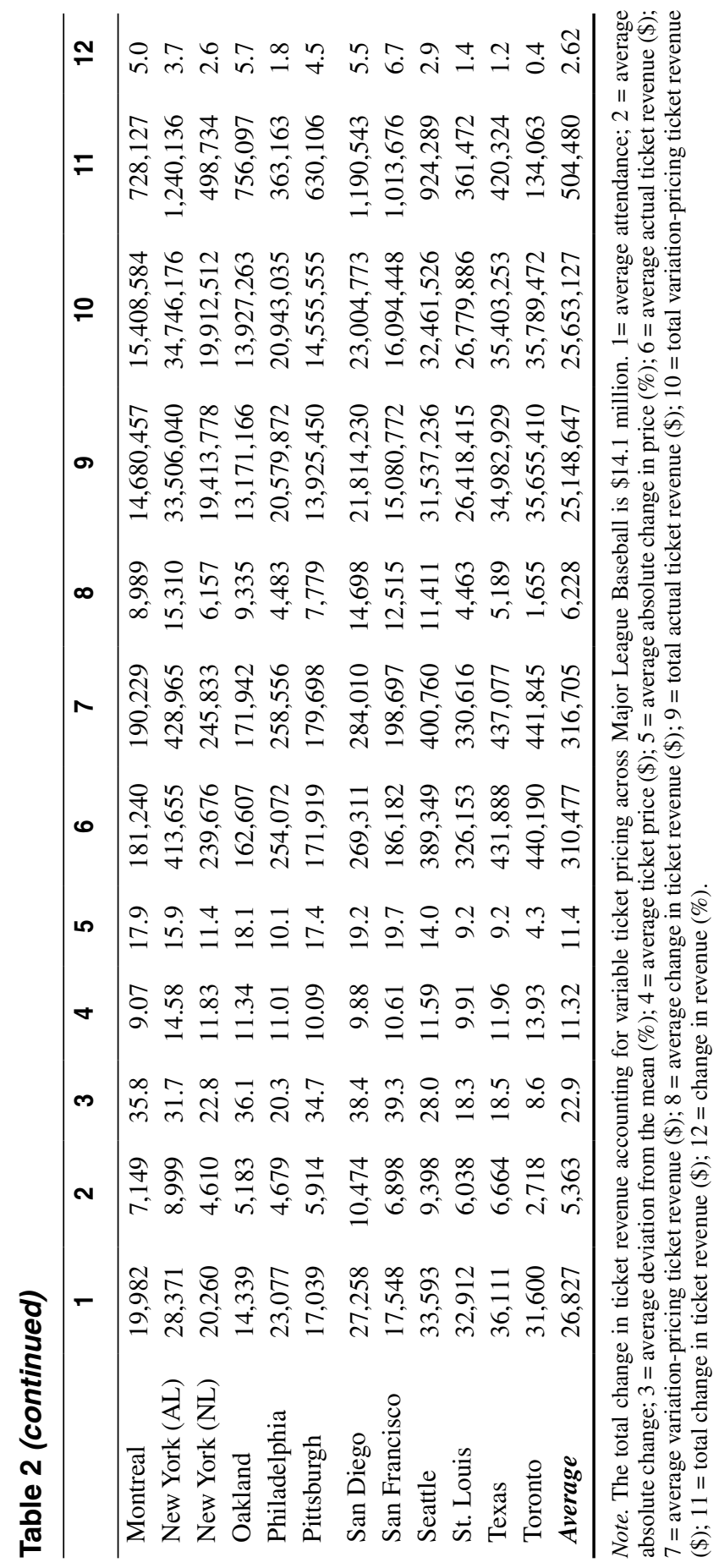


where kids and adults can enjoy themselves but not necessarily watch the game (George, 2003). These improvements not only increase demand but also lessen the importance that team performance uncertainty has on expected revenues.

At the same time, teams are beginning to use variable pricing in an attempt to manage shifting demand from game to game, given that they are unable to completely remove the variation. The theory on which this analysis is based is simply short-term revenue maximization with two goods that are complementary. Tickets and concessions are complementary goods. The demand for tickets is higher if concessions prices are lower because the overall cost of enjoying the game would be lower (Marburger, 1997; Fort, 2004). Similarly, the demand for concessions is higher if ticket prices are lower. The model consists of demand for tickets and a separate aggregate demand for nonticket products and services (hereafter referred to as concessions) that is affected by ticket price. This is where the complementarity between the two demand functions occurs. The following three models describe increasing degrees of complexity for the relationship between ticket demand and concessions demand. As shown, VTP policies should account for the extent to which there is complementarity between ticket demand and nonticket demand. For Model 1, let

$$
Q_{1}=\alpha_{1}-\beta_{1} P_{1}
$$

be the demand for tickets, where $Q_{1}$ is quantity demanded, $P_{1}$ is ticket price, and $\alpha_{1}$ and $\beta_{1}$ are scalars describing the shape of the demand curve. In this model, the demand for concessions, $Q_{2}$, will be unaffected by ticket prices. The optimal revenue maximizing ticket price is

$$
P_{1}^{*}=\frac{\alpha_{1}}{2 \beta_{1}} .
$$

The price elasticity of demand $\left(\eta_{P Q}\right)$ at $P_{1}^{*}$ and $Q_{1}^{*}$, where $Q_{1}^{*}=1 / 2 \alpha_{1}$, is equal to -1 , a common result from microeconomic theory. Thus, in the model, price is chosen where $\eta_{P Q}=-1$. This model is applicable for teams that do not share in concessions revenues or simply receive a fixed annual payment for concessions rights from a vendor, perhaps having sold them up front to build a new stadium. In general, much of the costs associated with operating a baseball team are fixed costs. The marginal costs of selling an extra ticket are low; hence, revenue maximization will be assumed in place of profit maximization. Relaxing this assumption adds a marginal cost term to the analysis, but does not change the fundamental findings. The marginal costs of MLB teams are unknown, and, therefore, the empirical analysis does not incorporate it.

Model 2 is applicable for teams that receive all or a share of concessions revenue. Let

$$
Q_{1}=\alpha_{1}-\beta_{1} P_{1}
$$

be ticket demand, as in Model 1. Furthermore, let $Q_{2}=Q_{1}$, meaning that each person who purchases a ticket also buys some concessions. Moreover, the price of concessions is exogenously determined by the concessionaire and will be noted by $\bar{P}_{2}$. Note that concessions do have a nonnegligible marginal cost that affects total profitability. A more complete model would include marginal cost in the final 
optimal ticket-price-setting equation. This would add unnecessary complexity, however, and, more important, would make it more cumbersome to compare how price is affected with Model 1 . The resulting optimal revenue maximizing ticket price is

$$
P_{1}^{*}=\frac{\alpha_{1}}{2 \beta_{1}}-\frac{\bar{P}_{2}}{2} .
$$

As seen in Equation 2.2, the revenue-maximizing, or optimal, ticket price is lower when accounting for the price of concessions (and any other nonticket products or services such as merchandise and parking) than it would be if it were set in a vacuum in which only ticket revenue is accounted for, as in Equation 1.2. This is consistent with findings in the review of literature mentioned previously. Specifically, $\left|\eta_{P Q}\right|=\left[\left(\alpha_{1}-\bar{P}_{2}\right) /\left(\alpha_{1}+\beta_{1} \bar{P}_{2}\right)\right]<1$, meaning that the elasticity for Model 2 is smaller in absolute value terms than for Model 1. The optimal ticket price is set in the inelastic portion of demand. It is predictable that for low concessions prices the impact of concessions revenue on ticket-price decision making is minimized. In fact, $\bar{P}_{2} \rightarrow 0, \eta_{P Q} \rightarrow-1$, which is the optimal price elasticity when not accounting for concessions revenues (Model 1).

Model 3 generalizes Models 1 and 2 by adding cross-price effects to ticket demand and concessions demand, exhibiting the notion that the total price of attending a game is what matters to customers, not just ticket price. Therefore, let

$$
Q_{1}=\alpha_{1}-\beta_{1} P_{1}-\gamma_{1} \bar{P}_{2}
$$

be ticket demand, where $\gamma_{1}$ is the incremental effect of concessions prices on ticket demand. The demand for concessions will be shown by

$$
Q_{2}=\alpha_{2}-\beta_{2} \bar{P}_{2}-\gamma_{2} P_{1} \text {. }
$$

As noted in the equation, ticket price, $P_{1}$, affects the demand for concessions in a negative way. If ticket prices are raised, the demand for concessions declines based on $\gamma_{2}$, the marginal propensity to purchase concessions based on ticket price changes. The optimal revenue-maximizing ticket price is

$$
P_{1}^{*}=\frac{\alpha_{1}}{2 \beta_{1}}-\frac{\left(\gamma_{1}+\gamma_{2}\right) \bar{P}_{2}}{2 \beta_{1}},
$$

with $P_{2}$ exogenous. Even though the concessionaire often sets concessions prices, removing this assumption does not change the direction of the impact, only the magnitude. Equation 3.3 shows that the ticket prices ought to be lower if fans care about concessions prices. Specifically, higher $\gamma_{1}$ or $\gamma_{2}$ leads to lower optimal ticket prices. The more sensitive customers are to the price of complementary goods and services, the lower ticket prices should be in order to maximize profits. Thus, it is important to account for cross-price effects when setting prices. Overall, the price elasticity for Model 3 might be higher or lower than for Model 2, depending on the relative magnitudes of $\beta_{1}, \gamma_{1}$, and $\gamma_{2}$. Like Model 2, however, the absolute value of the price elasticity for Model 3 is lower than for Model 1. In the analysis that follows, variable pricing outcomes will be determined under two scenarios-one without the cross effects (Model 1) and one with the cross effects (Model 3). Again, 
Model 1 pertains to teams that either do not receive any concessions revenue or receive a fixed payment in exchange for concessions rights. Model 3 applies to teams that receive a share of concessions revenues.

To be clear, these models do not assume profit maximization, win maximization, or something else; they only assume that a team's objectives are consistent throughout the season. For example, if a team is focused primarily on profits, it will set ticket and concessions prices in order to maximize the sum of both revenues. In a similar way, if a team is attempting to maximize wins, it will still want to price as a profit maximizer because its relevant costs are not variable. Such a team would likely spend more on players in order to improve winning than a profit-maximizing team would. The team would still want to set prices in order to maximize revenues from tickets and concessions, however, just as a profit-maximizing team would. An exception to this argument is if a win-maximizing owner chose to price below profit-maximizing levels in order to raise attendance (even though it is lowering revenues) to increase the impact of home-field advantage, which would increase the likelihood of winning more games and, therefore, satisfy his or her objectives.

The models also do not need to assume linear demand functions. Linear demand is chosen for simplicity. As described in the next section, nonlinear demand changes the magnitudes of the findings. Using linear demand generates more conservative findings - the gains from variable pricing are lower. The empirical analysis operationalizes this by noting that regardless of an owner's objectives (winning, profits, or a combination of the two), it is assumed that prices are set to maximize those objectives. For a particular game it might be that prices are too low or too high given demand, but because one price is charged for the entire season, it is objective maximizing on average.

One hypothesis stemming from these models is that adoption of VTP would improve revenues for MLB teams. Another hypothesis is that for those teams who are adjusting prices, the amount of adjustment is correct. For instance, the Cardinals had only raised their prices for VTP games by $\$ 2$ for 2002. In contrast, the Rockies have had prices for particular seats that varied by as much as \$6 (Rovell, $2002 \mathrm{~b}$ ). This analysis will provide a benchmark for how much teams should be adjusting their prices.

It is important to note that there are public relations issues that play a role in VTP. For example, the Nashville Predators have been thinking about incorporating VTP but fear a negative fan backlash at a time when they are trying to build a loyal fan base (Cameron, 2002). A team might therefore opt to raise its prices only nominally to see if there is a backlash in which fans react with an emotional response that actually shifts demand (not slides along demand, as price changes are expected to do). This analysis ignores any public relations issues.

\section{Method}

The first analysis tested Model 1 in which only ticket pricing is accounted for. The methodology involved analyzing how demand for each game deviated from the average demand for each team. For example, as shown in Figure 1, Point A is on the average demand curve for the Atlanta Braves. It represents the actual average ticket price $(\$ 13.06)$ and average attendance $(35,793)$. The slope of the demand curve is 
based on the assumption that the price elasticity equals -1.0 (This assumption can be relaxed without loss of generality. For instance, it can be assumed that the team prices on the inelastic portion of demand are at, say, -0.75.) Therefore, slope can be determined from price, quantity, and elasticity.

Point B is the actual price (still \$13.06) and attendance $(48,961)$ for the Braves' home opener. This is the demand for that game, given the price. Looking at actual attendance reveals the demand. As described in Theoretical Foundations, ticket prices, on average, were optimal for the Braves. It was assumed that each team was doing its best at determining ticket prices and was setting them to account for the average expected demand for the entire season. Therefore, the price elasticity was set at -1.0 at Point A. At Point B the elasticity changed to -0.73 , thus it is a suboptimal price. Raising price to $\$ 15.46$ (Point $\mathrm{C}$ ) changed the elasticity back to -1.0 and lowered attendance to 42,371. Revenue was then calculated for this new price and quantity and compared with the actual revenue from that game (measured by multiplying the actual average price charged for that game with the actual quantity of spectators for that game). These measurements were taken for each game of the season for each team in order to be able to see how adjusted ticket prices affect revenue. See the Appendix for a brief description of the calculations.

The previous example used linear demand. If a slightly curved demand function is used, the gains from variable pricing would be higher because the loss in number of attendees is compensated by higher pricing as a result of the curvature of the demand function. As shown in Figure 2, the simplified demand function, Curved Increase, had an optimal price point at D, whereas the linear demand function's optimal price point was C. Table 3 provides the details of each of these demand functions. Each demand function was shifted the same amount (as shown by Point B). Figure 3 shows the associated revenue at each point. The curved demand resulted in higher revenue (\$18.52) from variable pricing (Point $D$ ) than for the linear demand ( $\$ 16.00$ at Point $C$ ). Thus, an equal increase in the number of attendees will lead to lower gains using linear demand instead of curved demand. This is also true for a low-demand game. Point $\mathrm{G}$ is the optimal price for the lineardemand function and Point $\mathrm{F}$ maximizes revenue for the curved demand. As shown in Table 3, the curved-demand function resulted in higher revenues from VTP. This was not surprising - for a given price, a curved-demand function will result in more attendees (higher quantity) than a linear-demand function. A constant elasticity of demand function (CED) has more curvature than the ones shown in Figure 2. Revenue is constant regardless of price for CED. Prices can be set at any level and yield the same revenue. CED is an unrealistic demand function for baseball. An even more extreme demand function, a super-curved demand in which the degree of curvature is greater than that for CED, is such that the revenue function looks U shaped, not hill shaped, as in Figure 3. In that case, revenue-maximizing prices are either very low or very high and unlikely to be consistent with reality in baseball. An example of this type of demand function is $P=1 / \ln (Q)$. The use of linear demand in the subsequent analysis is conservative in that the gains from variable pricing are a lower bound of what would be the case if demand functions for baseball are curved. This reason, along with simplicity and a lack of research about the shape of baseball demand functions, was justification for using linear demand in the following analysis. Parallel shifts of the demand function were 


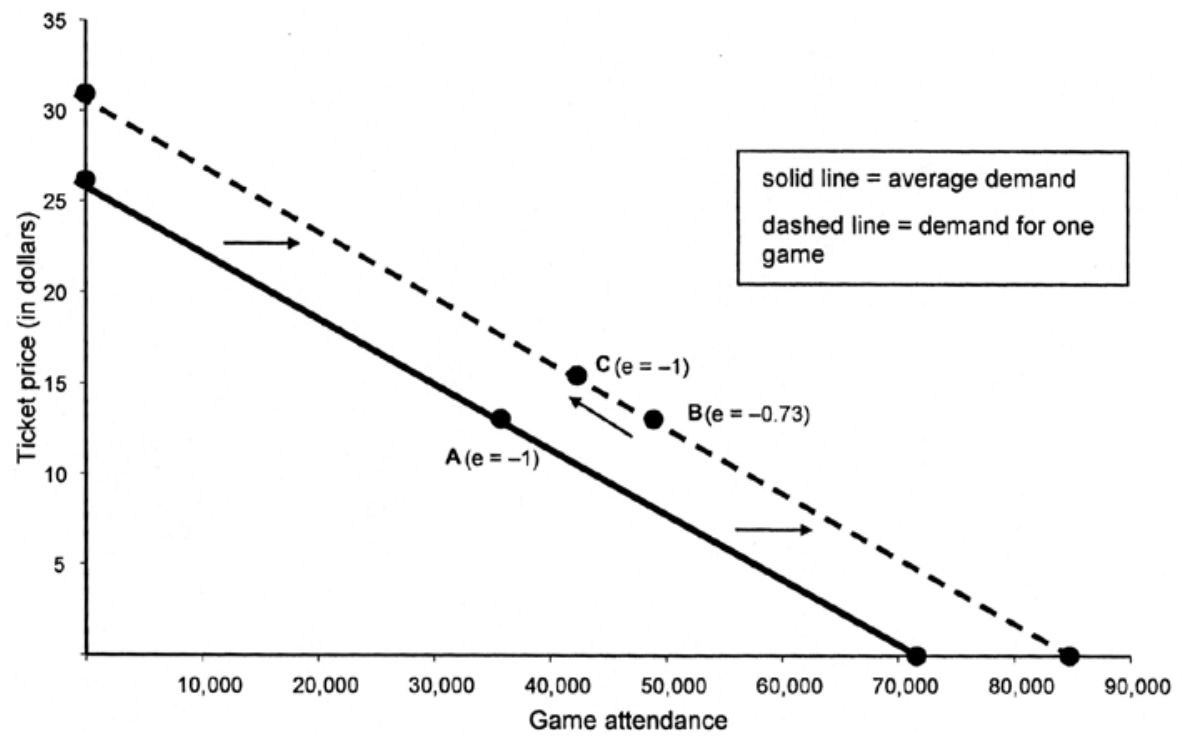

Figure 1 - Optimal variable pricing adjustment for Atlanta.

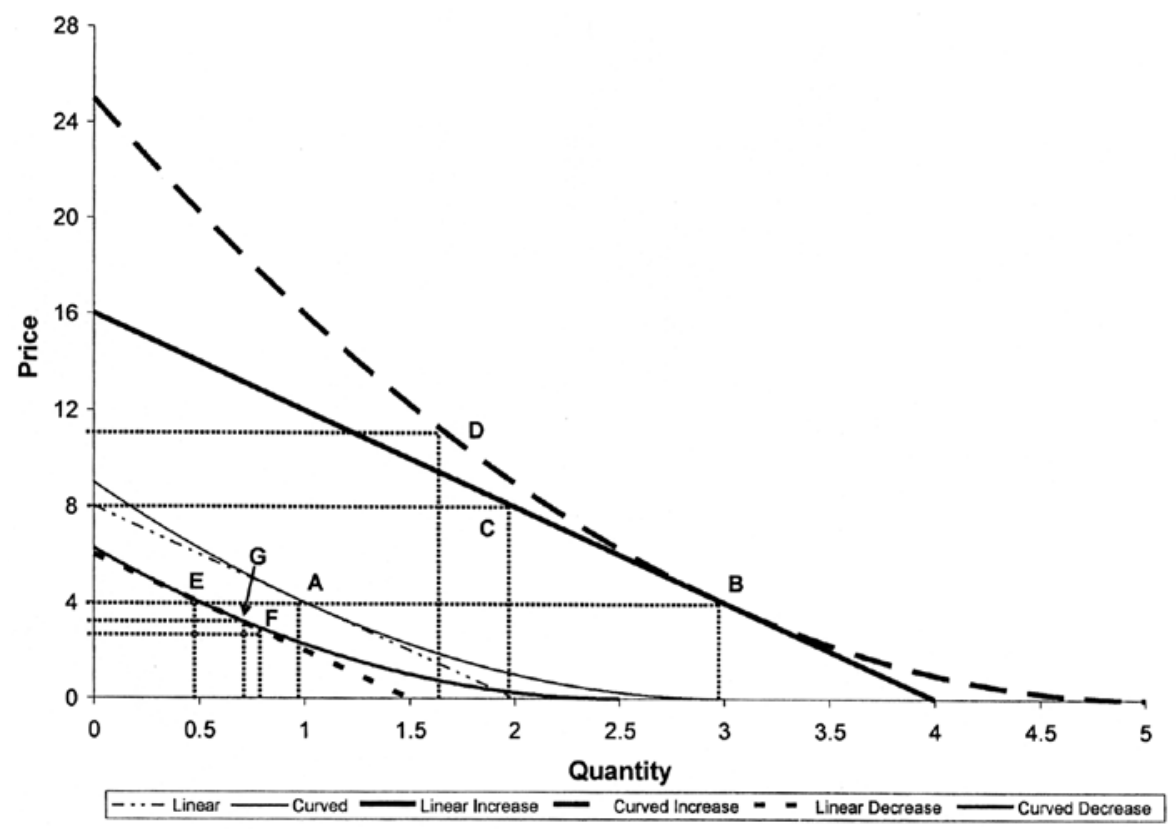

Figure 2 - Curved demand functions versus linear demand functions. 


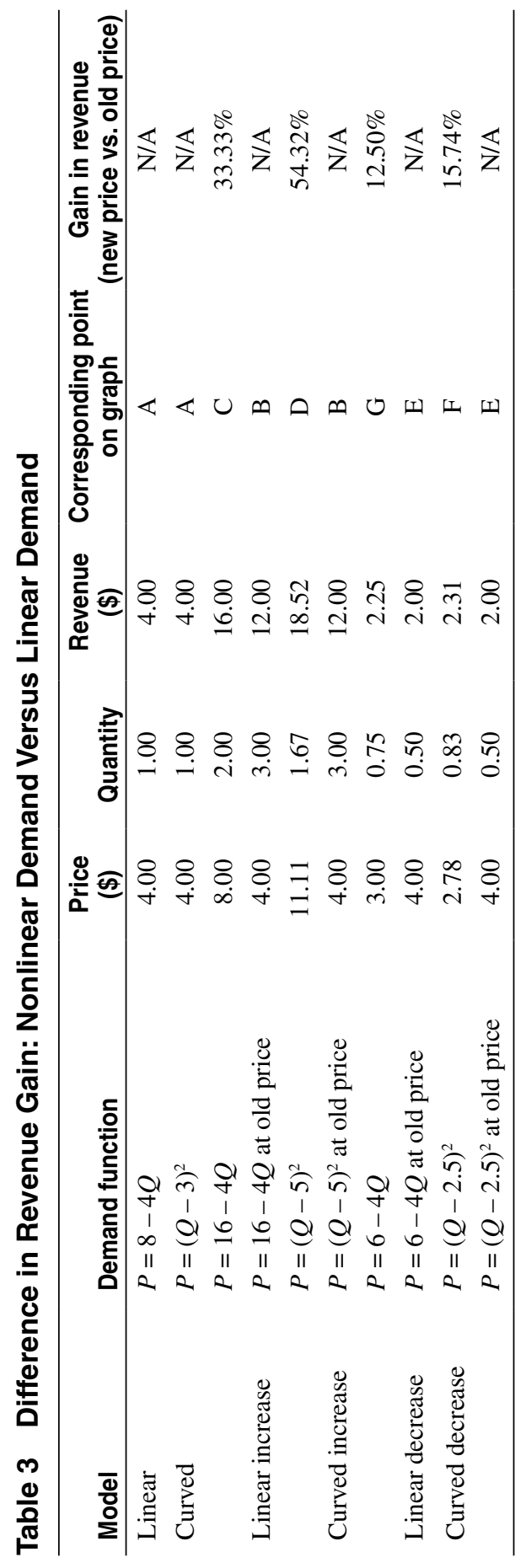




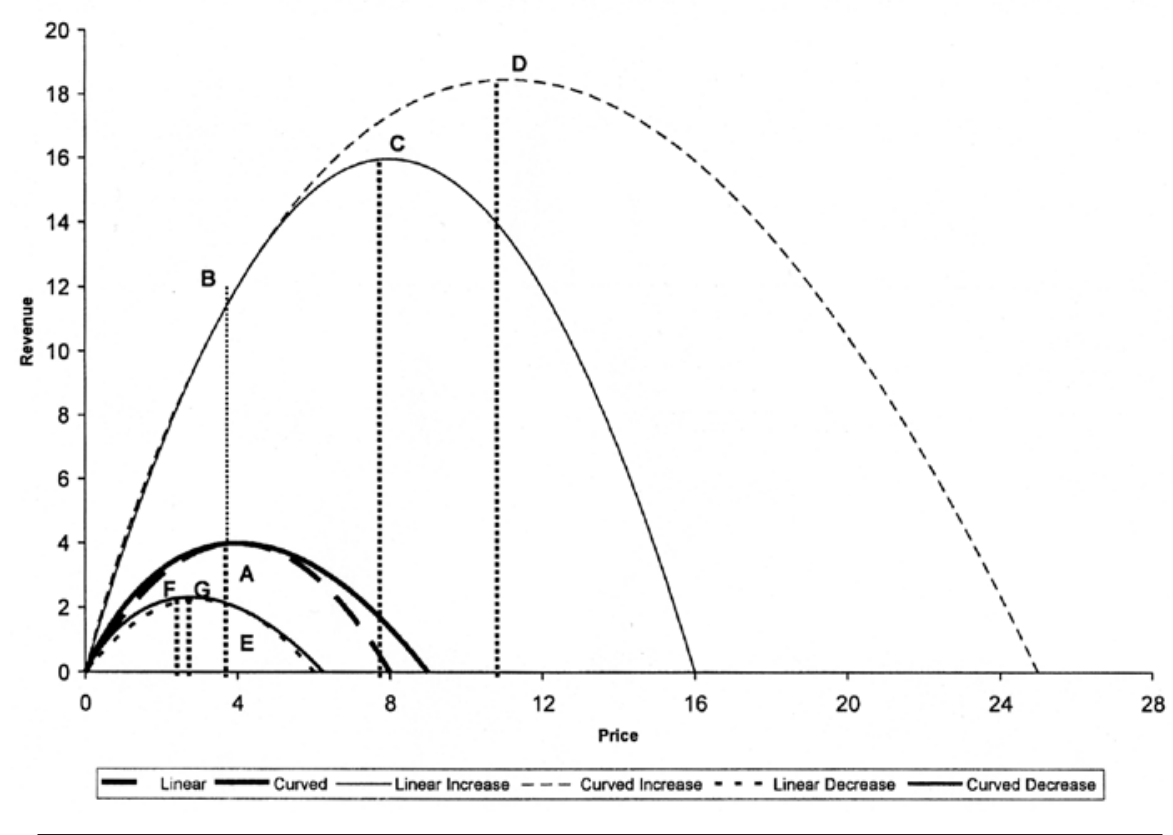

Figure 3 - Revenue functions of curved demand versus linear demand.

also assumed because of simplicity and a lack of relevant research showing other types of shifts. Unfortunately, attendance by seat location and specific price is not publicly available. If it were, one could examine how much demand changes per price point to get a sense of the nature of the shift in demand.

The subsequent analysis accounted for the possibility that stadium capacity prevented the true demand from being revealed. In other words, sellouts typically imply that there was excess demand beyond the capacity of the stadium. The standard result would be to raise prices until the entire stadium is full and there are no persons outside who are interested in attending the game at the new higher ticket price. In order to determine how much to raise prices, the amount of excess demand needed to be estimated. This was done using a censored regression, which can forecast the true demand as though there were not a capacity constraint. It used information from uncensored observations (those without a capacity constraint as shown by not having sold out) to estimate what would have happened without the constraint.

The censored regression used attendance as the dependent variable and various demand factors listed in the second data set as the independent variables. The result was an empirical model that can be used to forecast what attendance would have been for the capacity-constrained games. The methodology was the same as the first analysis, but used the new forecasted attendance when estimating optimal prices and resulting revenue.

The final analysis included the focus of Model 3-how the prices of complementary goods (tickets and concessions) affect the demand and, hence, optimal price for each other. This analysis created a single demand for the joint product of tickets 
and concessions, with concessions prices exogenously determined. According to Financial World, these nonticket revenues made up 35\% of ticket plus nonticket revenues for MLB teams during 1996 (Badenhausen \& Nikolov, 1997). For every dollar spent at a stadium by a patron, 35 cents were spent on concessions, merchandise, and parking. Therefore, the nonticket price for each team was set at $54 \%$ $(54 \%=35 \% /[1-35 \%])$ of the ticket price because team-specific data on nonticket revenue was unavailable. Given this new joint-demand function, optimal prices were set for each game as in the two previous analyses. The censored regression forecasts of attendance were used in this analysis. This analysis accounted for the combined product of tickets and concessions, so, as a group, the demand elasticity was -1.0 . Given that the concessions price was fixed and positive, the new optimal ticket price would be on the inelastic portion of demand. This was consistent with the findings in the literature.

These three analyses determined the optimal variable ticket price for nearly every game for the 1996 MLB season. The 1996 season was used because during that year no MLB team used VTP. It should be noted that 1996 was the first full season after the strike of 1994-95. It is possible that the findings here are not typical of a MLB season. An important factor in this analysis, however, is the shift in demand from game to game. Attendance for the 1996 season has a standard deviation that is only $5 \%$ greater than attendance for 2003. The use of more recent data, which would include teams using VTP, raised validity concerns with the attempt to predict additional revenue generated through the use of VTP. The use of the 1996 data allows the analysis to be consistent across all teams. The analysis showed what the ticket price should have been with the corresponding results if every team had participated in optimal VTP. In order to achieve this, data for 2,193 of the 2,268 scheduled regular season games were used. The few games not used in the analysis either lacked sufficient data, were double-headers, or were rainouts that were never made up.

The data were broken into two sets. One set was used to forecast optimal VTP. It included actual attendance, average ticket price, stadium capacity, and average concessions expenditures. Attendance data came from www.sportsline. com, ticket price data from Team Marketing Report, stadium capacity data from www.ballparks.com, and concessions information from Financial World's financial report on baseball for the 1996 season (Badenhausen \& Nikolov, 1997). Table 2 (columns 1 and 4 ) shows average attendance and average ticket price for each team for the 1996 season.

The second set of data was used to make an adjustment to demand for games that are censored by capacity constraints, namely games that are sold out or nearly sold out. This adjusted demand was then used in the VTP analysis. This data set contained actual attendance, the number of wins by the home team and visiting team in the previous season, the population of the local Consolidated Metropolitan Statistical Area (CMSA; term used by the U.S. Census Bureau), indicator variables for opening day, a new stadium, a weekend game, and a game in April. The data set came from www.sportsline.com, except population, which was obtained from the U.S. Census Bureau. Table 4 contains summary statistics of the data. 


\section{Table 4 Summary Statistics of the Censored Regression Data}

\begin{tabular}{lrrrr}
\hline & $\boldsymbol{M}$ & \multicolumn{1}{c}{$\boldsymbol{S} \boldsymbol{D}$} & Minimum & Maximum \\
\hline Game attendance & 26,868 & 11,852 & 6,021 & 57,467 \\
Home team's previous season wins & 81.92 & 10.02 & 56 & 100 \\
Visiting team's previous season wins & 81.99 & 10.11 & 56 & 100 \\
Opening day & 0.008 & 0.090 & 0 & 1 \\
Weekend game & 0.477 & 0.499 & 0 & 1 \\
New stadium & 0.215 & 0.411 & 0 & 1 \\
Population of CMSA & $5,997,132$ & $4,774,503$ & $1,640,831$ & $18,107,235$ \\
Games played during April & 0.162 & 0.368 & 0 & 1 \\
\hline
\end{tabular}

Note. CMSA = Consolidated Metropolitan Statistical Area, a measure of local population from the U.S. Census Bureau.

\section{Results}

Based on the estimates from the test of Model 1, if the Atlanta Braves, for example, had raised ticket prices for the opening game, actual attendance would have been 42,371 , with actual ticket revenues increasing by $\$ 15,817$, or $2.5 \%$ for that game. An elasticity of -1.0 implies revenue maximization. The analysis, however, could have begun with any elasticity as long as the resulting elasticity at Point $C$ is the same as that at Point A (see Figure 1). Therefore, this does not require revenue maximization or profit maximization, only consistency in terms of the objectives of the franchise throughout the season.

Continuing with the Braves example, Table 5 shows the results for every odd home game. The findings show that there are fewer games that have excess demand (although they have a higher average excess demand) than there are games that have lower demand than average (Figure 4). In fact, in 30 out of the 81 Braves' home games, demand exceeded the average, and the average optimal price increase is estimated to be $11.0 \%$, whereas the average decreased price is estimated to be $-6.5 \%$. Also, as expected, the high-demand games generally are for an entire series. Thus, one VTP strategy for the Braves would be to use variable pricing for series that are in high demand and simply lower prices on the other games in general (as a public relations move and to increase overall revenues).

The bottom row of Table 5 shows the average results for the entire Braves season. The average per-game revenue increase for the season is $\$ 4,367$, or $0.9 \%$. The results for each team are shown in Table 2. Columns 8 and 12 show the result from Table 5 for the Braves. Over the course of the full season, the Braves could have increased their ticket revenues by $\$ 353,706$, or $0.9 \%$.

Variable pricing would have yielded an average of approximately $\$ 504,000$ per year in additional revenue for each MLB team, ceteris paribus, or over $\$ 14$ million for the league as a whole. This amounts to only about a $2.6 \%$ increase above what occurs when prices are not varied, as shown in Table 2 . The amount of variation 


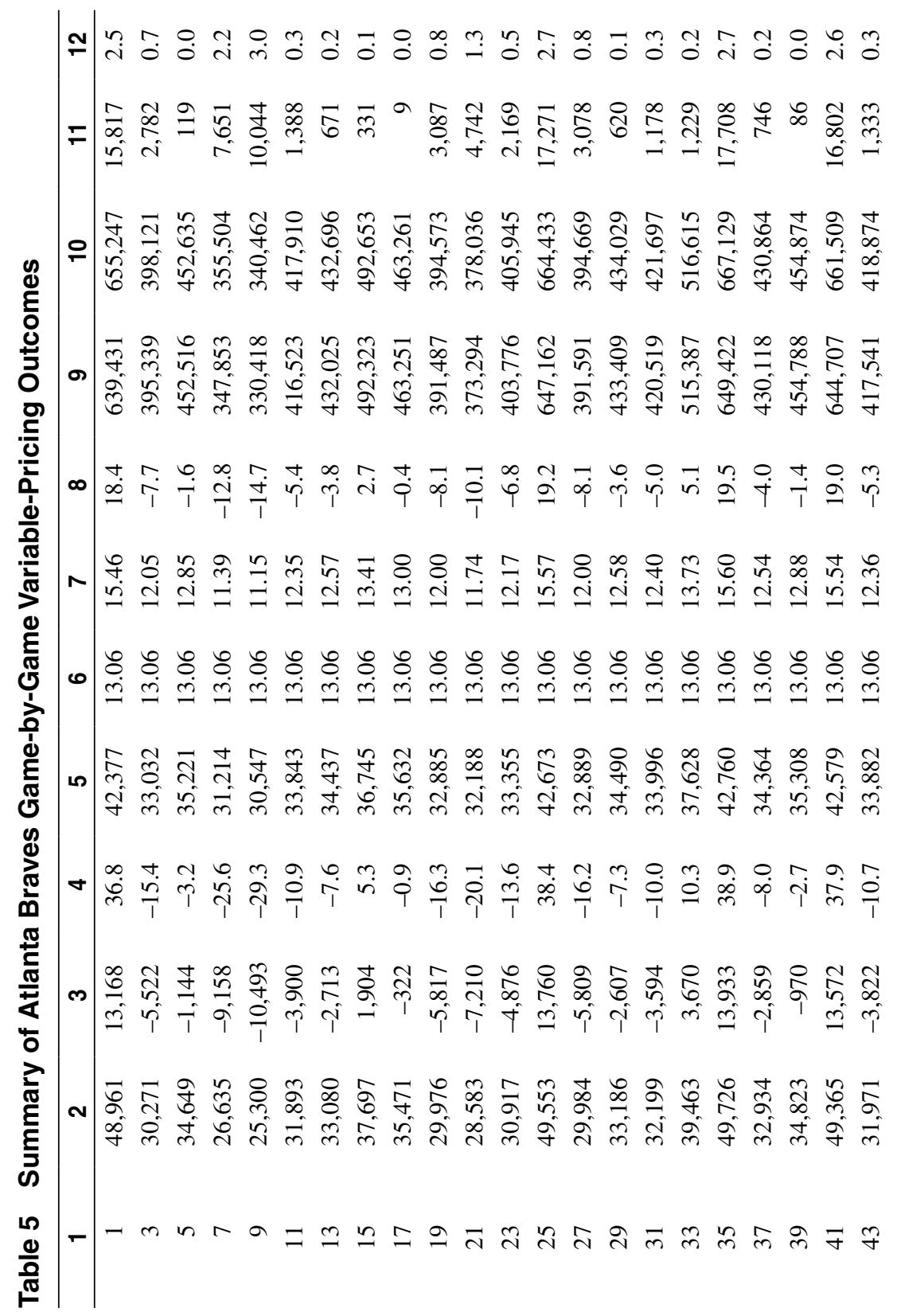




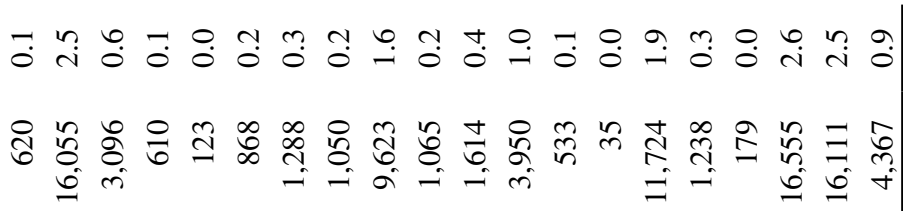

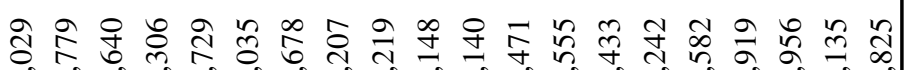

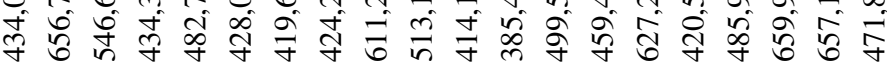

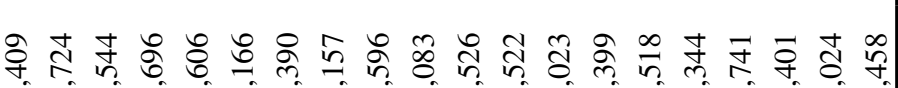

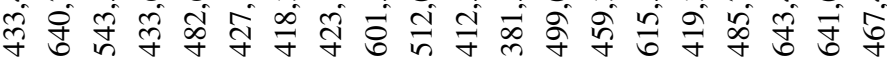
ம் 舟

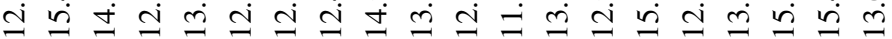

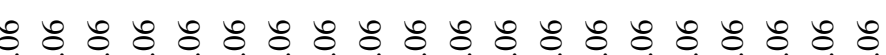

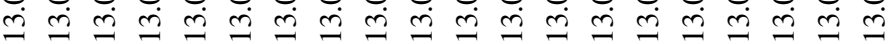

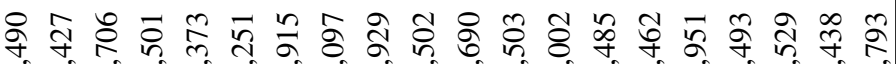

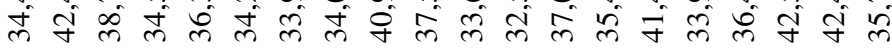

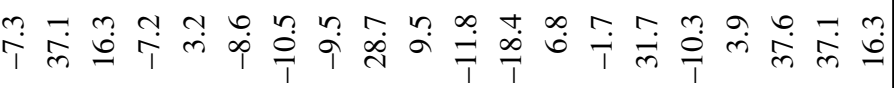

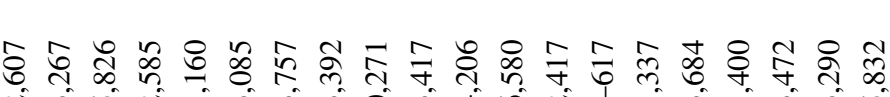

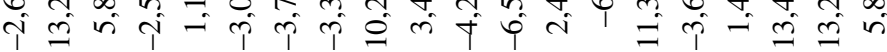

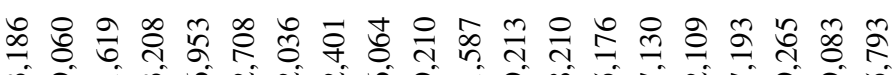

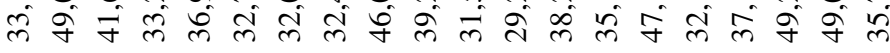

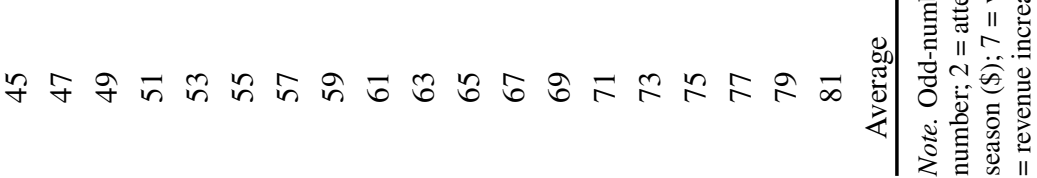




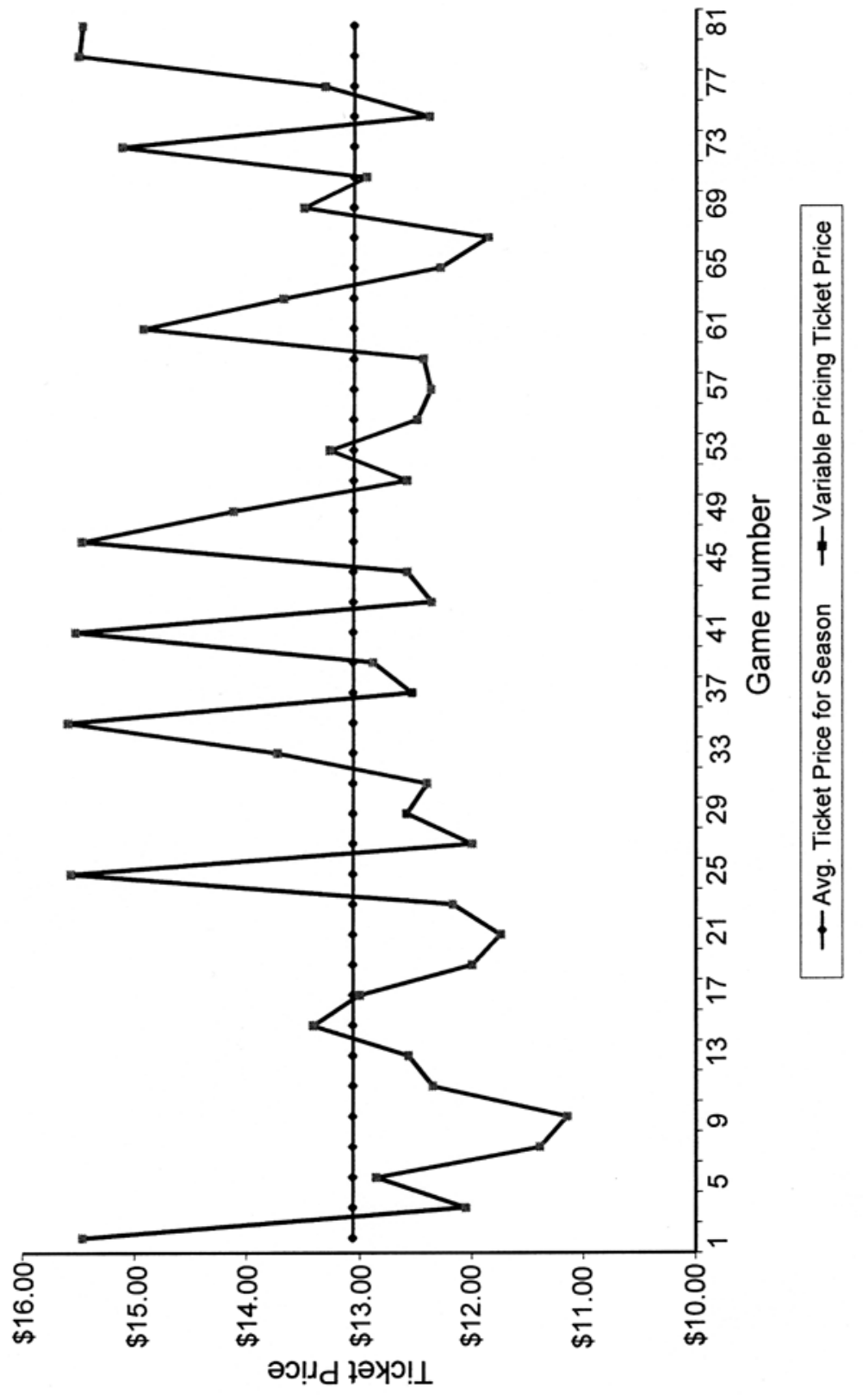

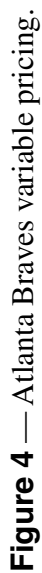


in ticket prices is just over $11 \%$ on average. The fact that such a large price swing only yields a revenue swing four times smaller is simply based on the large change in attendance that occurs when prices are varied. This occurs with all downward sloping demand curves and is not unique to baseball. For the 1996 season, the largest revenue gain would have been for the New York Yankees, which would have generated an extra $\$ 1.24$ million in ticket revenue, or a 3.7\% increase. The largest percentage revenue gain would have been for the San Francisco Giants. The Giants would have seen an estimated $6.7 \%$ increase in revenue, or \$1.01 million, if they had used optimal VTP. The smallest amount of impact would have been for the Colorado Rockies, which averaged only plus or minus 80 patrons in absolute deviation from the mean attendance per game throughout the 1996 season. In fact, teams with the lowest average attendance benefit the most from variable pricing. This is not surprising because those teams tend to have the highest variation in attendance, allowing them to gain from dynamic pricing.

The Rockies would gain the least from VTP because they had many sellouts in 1996. As described in the Method section, a censored regression is carried out in order to forecast the true demand above the capacity constraint. Although there are many more factors that affect game-by-game attendance than those used here, this analysis used only those factors known before ticket-price setting occurred. Thus, only factors known before the beginning of the season are used in order to be consistent with what would be known by team management when setting prices. The Wald chi-squared test of significance showed that the model was significant at the $.001 \%$ level, with a Wald statistic of 906.6 . A potential problem is that the errors for a series between two teams might not be independent. It is expected that across different groups of games (a three-game series, for example) there is independence of the errors but not necessarily in each group. This type of clustered correlation leads to understating the standard errors. A robust estimator of the variance is used to correct the standard errors. There is no evidence of multicollinearity among the independent variables. As expected, there is evidence of omitted variables missing from the regression. As explained, performance-specific factors that are only known to price setters once the season has begun, such as the home pitcher's earned-run average at that point in the season, were omitted. The variance-inflation factor (VIF) averaged 1.19 across the group of variables tested for multicollinearity, with the largest VIF at 1.58. The Ramsey RESET test shows evidence of omitted variables with an F-statistic of 29.67.

Table 6 shows the results of the censored regression. The signs of the coefficients are as expected. Out of 2,193 games, only 109 were sold out. A sellout is defined, for these purposes, as any game in which actual attendance is $99.0 \%$ or higher of stadium capacity. The estimate of attendance for these 109 games is based on the predicted values from the censored regression.

As shown in Table 7, 10 teams had adjustments to their attendance based on the censored regression. The results are similar to that of Table 2, except column 13 shows the gain for those 10 teams in Table 7 if they account for the capacity constraint when adjusting their prices for their VTP strategy. Overall, adjusting for demand beyond stadium capacity raises the increased revenue from VTP policies from $\$ 14.1$ million to $\$ 16.5$ million for the league as a whole.

The final analysis addressed Model 3 from the Theoretical Foundations section by accounting for nonticket revenues such as concessions, merchandise, and 


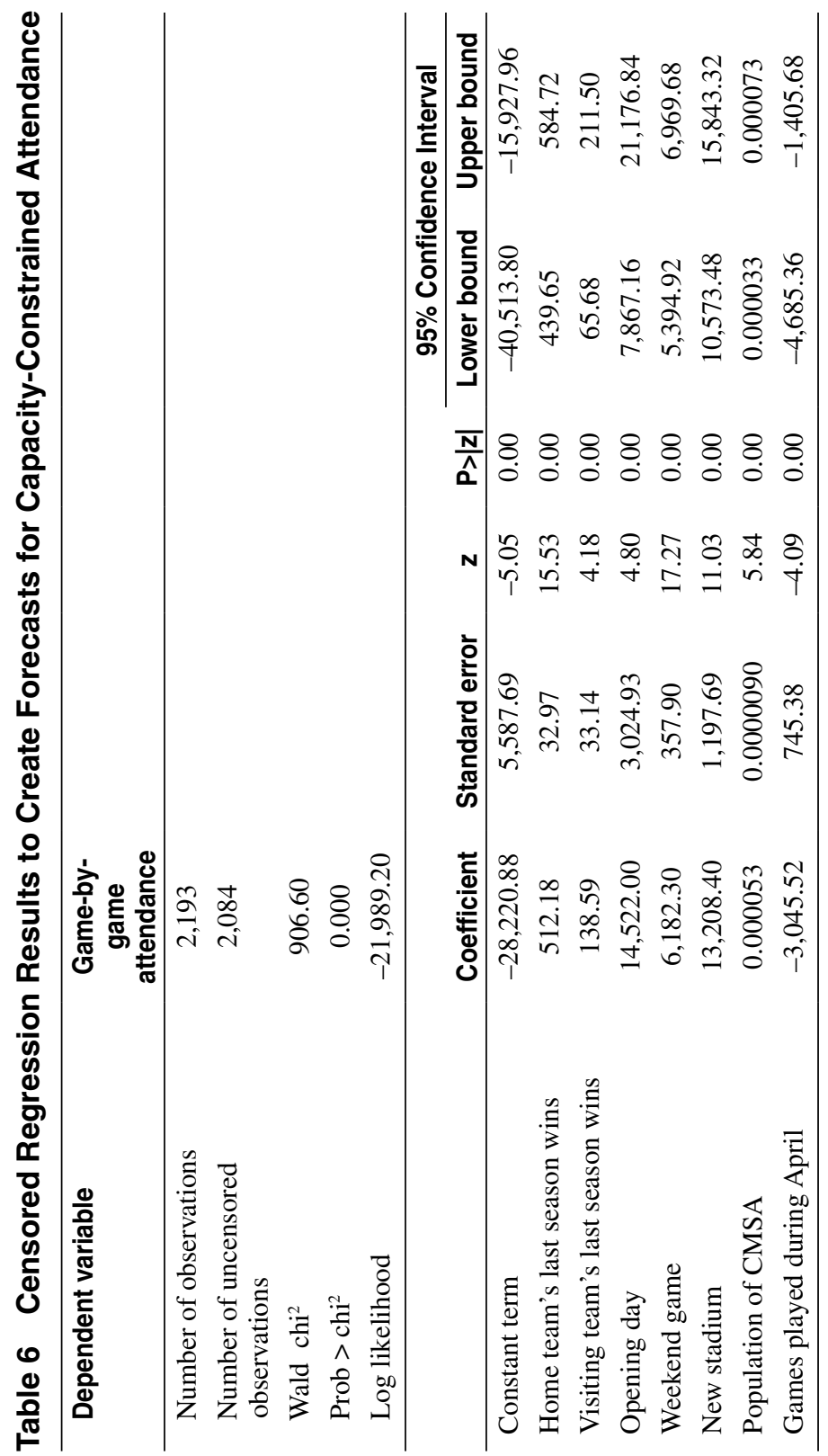




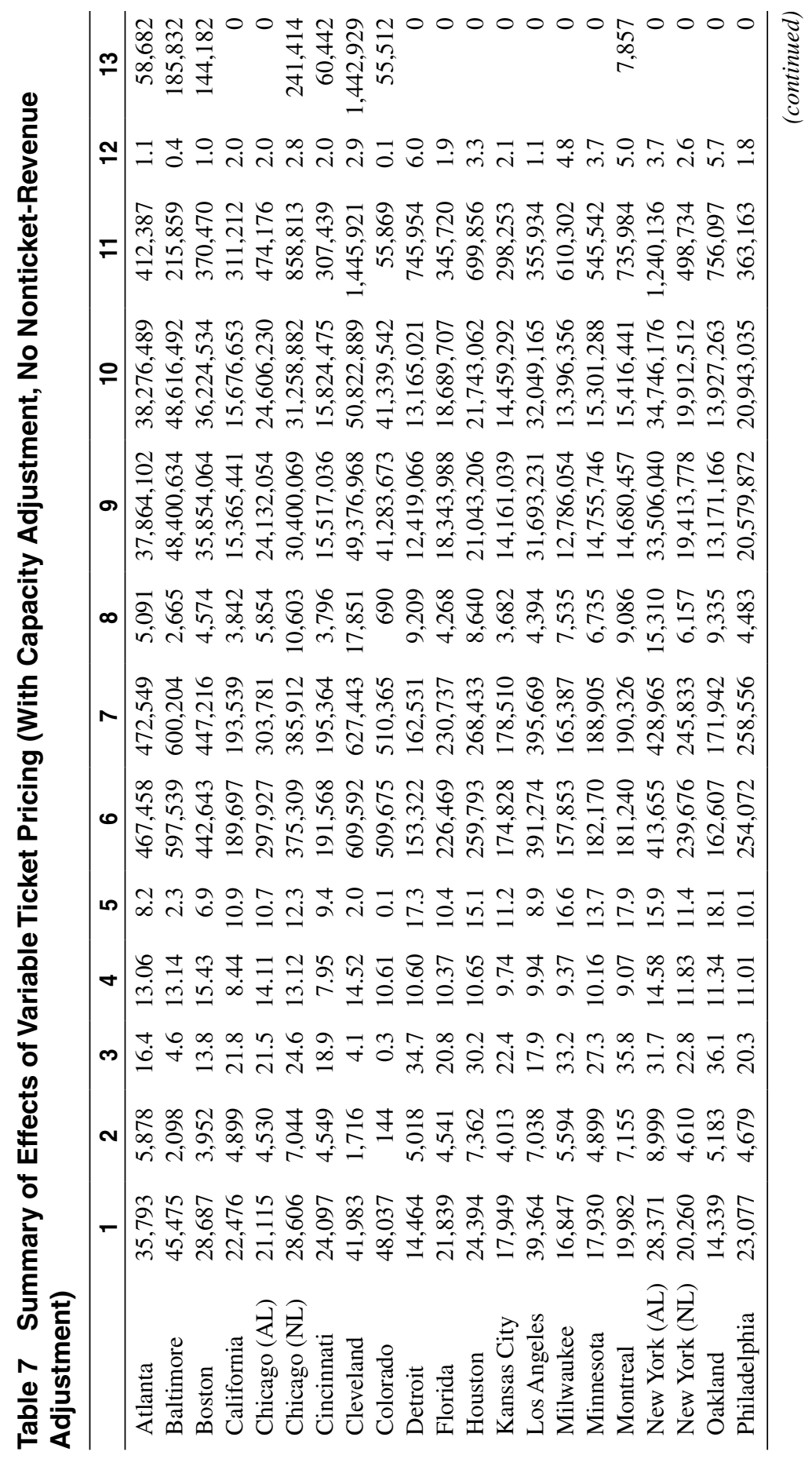




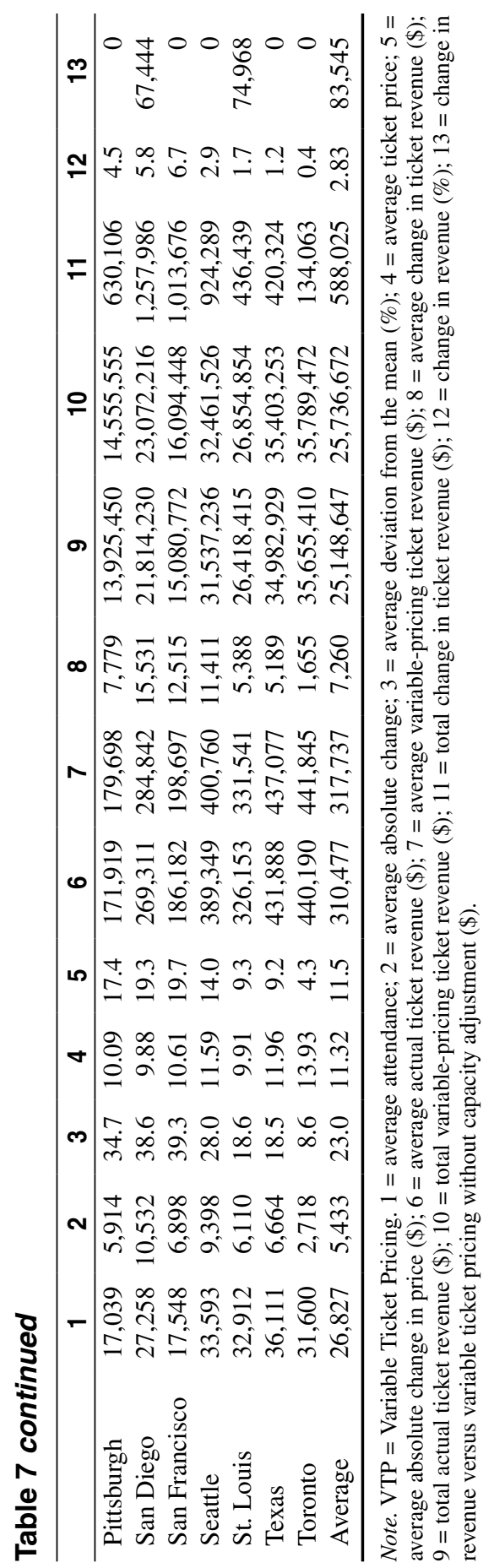


parking. Table 8 shows the results of allowing the team to vary ticket prices while accounting for nonticket prices in order to maximize its objectives. Columns 9, 10, and 11 in Table 8 illustrate that the average team would have gained $\$ 911,000$ in ticket and nonticket revenue by adopting a VTP policy while accounting for nonticket prices. The league overall would have gained $\$ 25.5$ million. The Cleveland Indians would have earned the most, over $\$ 2.2$ million, from such a policy.

\section{Discussion}

This analysis has shown that MLB could have increased ticket revenues by approximately $2.8 \%$, or $\$ 16.5$ million, and total stadium revenues by about $\$ 25.5$ million for the 1996 season if teams used VTP. Total revenues in MLB are estimated to have grown from $\$ 1.78$ billion in 1996 to approximately $\$ 4.3$ billion in 2003 , or $250 \%$. Similar changes in the effect of VTP strategies, as discovered in this study, would yield nearly $\$ 40$ million in ticket revenue and over $\$ 60$ million in ticket plus nonticket revenue for MLB. Therefore, it behooves team owners and the league office to consider and implement VTP strategies, especially because teams and the league are constantly searching for ways to increase revenues.

The San Francisco Giants would have seen an estimated $6.7 \%$ increase in ticket revenue, or \$1.01 million, if they had used optimal VTP in 1996. It is interesting that the Giants had considered using VTP since the 1996 season because they had noticed a huge variation in attendance patterns at Candlestick Park, the team's then-home facility (King, 2002a). In addition to weather issues (pleasant for day games but frigid for night) in their facility, the Giants of the mid-1990s occasionally fielded teams of lower quality. The results of this study would strongly suggest that teams in similar facility or on-the-field talent situations maximize their revenues through VTP.

The results of this study support the use of VTP both to increase and decrease prices from average seasonal levels. The data showed fewer games with excess demand than those with diminished demand. The selected games with excess demand deviated, however, from the mean at a greater rate than those with decreased demand. Currently, most MLB teams have focused their VTP strategies on the revenue potential of increased prices from highly demanded games (King, 2002a). It appears that some teams, however, have begun to realize the potential benefit of attracting fans to less desirable contests by lowering prices (King, 2002b). The New York Yankees sold \$5 tickets in certain sections of Yankee Stadium on Mondays, Tuesdays, and Thursdays in 2003 (King, 2003).

Lowering ticket prices for less desirable games would potentially create more positive relationships between teams and local municipalities. MLB teams have often been chastised for seeking subsidies for new revenue generating facilities that are financially inaccessible to many taxpayers (Pappas, 2002; O'Keefe, 2004). Given the number of games in a typical season for which demand is below the yearly average (Figure 4), lowering prices creates an opportunity for teams to potentially attract new or disenfranchised fans and presents local governments with a more favorable reaction to their public-policy decisions supporting the local franchise. Marketing less desirable games with lower ticket prices as "value" games, as the Chicago Cubs, Colorado Rockies, New York Mets, Tampa Bay Devil Rays, and Toronto Blue Jays did in 2004, allows teams to reach market segments perhaps 
Table 8 Summary of Effects of Variable Ticket Pricing (With Capacity Adjustment and Nonticket-Revenue Adjustment), Part 1

\begin{tabular}{|c|c|c|c|c|c|c|c|c|}
\hline & 1 & 2 & 3 & 4 & 5 & 6 & 7 & 8 \\
\hline Atlanta & 35,793 & 5,878 & 16.4 & $\$ 13.07$ & 7.18 & 467,458 & 475,184 & 732,451 \\
\hline Baltimore & 45,475 & 2,098 & 4.6 & $\$ 13.16$ & 7.23 & 597,539 & 601,064 & 930,316 \\
\hline Boston & 28,687 & 3,952 & 13.8 & $\$ 15.46$ & 8.49 & 442,643 & 449,290 & 693,186 \\
\hline California & 22,476 & 4,899 & 21.8 & $\$ 8.44$ & 4.64 & 189,697 & 195,652 & 299,985 \\
\hline Chicago (AL) & 21,115 & 4,530 & 21.5 & $\$ 14.11$ & 7.76 & 297,927 & 307,000 & 470,860 \\
\hline Chicago (NL) & 28,606 & 7,044 & 24.6 & $\$ 13.16$ & 7.22 & 375,309 & 391,059 & 598,164 \\
\hline Cincinnati & 24,097 & 4,549 & 18.9 & $\$ 7.96$ & 4.37 & 191,568 & 197,327 & 302,814 \\
\hline Cleveland & 41,983 & 1,716 & 4.1 & $\$ 14.73$ & 7.99 & 609,592 & 632,454 & 972,537 \\
\hline Colorado & 48,037 & 144 & 0.3 & $\$ 10.62$ & 5.84 & 509,675 & 510,557 & 791,065 \\
\hline Detroit & 14,464 & 5,018 & 34.7 & $\$ 10.60$ & 5.83 & 153,322 & 167,596 & 251,923 \\
\hline Florida & 21,839 & 4,541 & 20.8 & $\$ 10.37$ & 5.70 & 226,469 & 233,085 & 357,643 \\
\hline Houston & 24,394 & 7,362 & 30.2 & $\$ 10.65$ & 5.86 & 259,793 & 273,185 & 416,071 \\
\hline Kansas City & 17,949 & 4,013 & 22.4 & $\$ 9.74$ & 5.36 & 174,828 & 180,535 & 276,690 \\
\hline Los Angeles & 39,364 & 7,038 & 17.9 & $\$ 9.94$ & 5.47 & 391,274 & 398,086 & 613,286 \\
\hline Milwaukee & 16,847 & 5,594 & 33.2 & $\$ 9.37$ & 5.15 & 157,853 & 169,531 & 256,350 \\
\hline Minnesota & 17,930 & 4,899 & 27.3 & $\$ 10.16$ & 5.59 & 182,170 & 192,609 & 292,802 \\
\hline Montreal & 19,982 & 7,155 & 35.8 & $\$ 9.07$ & 4.99 & 181,240 & 195,308 & 295,006 \\
\hline New York (AL) & 28,371 & 8,999 & 31.7 & $\$ 14.58$ & 8.02 & 413,655 & 437,386 & 664,896 \\
\hline New York (NL) & 20,260 & 4,610 & 22.8 & $\$ 11.83$ & 6.51 & 239,676 & 249,220 & 381,042 \\
\hline Oakland & 14,339 & 5,183 & 36.1 & $\$ 11.34$ & 6.24 & 162,607 & 177,076 & 266,509 \\
\hline Philadelphia & 23,077 & 4,679 & 20.3 & $\$ 11.01$ & 6.06 & 254,072 & 261,022 & 400,762 \\
\hline Pittsburgh & 17,039 & 5,914 & 34.7 & $\$ 10.09$ & 5.55 & 171,919 & 183,977 & 278,532 \\
\hline San Diego & 27,258 & 10,532 & 38.6 & $\$ 9.89$ & 5.43 & 269,311 & 293,227 & 441,505 \\
\hline San Francisco & 17,548 & 6,898 & 39.3 & $\$ 10.61$ & 5.84 & 186,182 & 205,580 & 307,980 \\
\hline Seattle & 33,593 & 9,398 & 28.0 & $\$ 11.59$ & 6.37 & 389,349 & 407,036 & 621,177 \\
\hline St. Louis & 32,912 & 6,110 & 18.6 & $\$ 9.92$ & 5.45 & 326,153 & 334,308 & 513,889 \\
\hline Texas & 36,111 & 6,664 & 18.5 & $\$ 11.96$ & 6.58 & 431,888 & 439,931 & 677,470 \\
\hline Toronto & 31,600 & 2,718 & 8.6 & $\$ 13.93$ & 7.66 & 440,190 & 442,756 & 684,860 \\
\hline Average & 26,827 & 5,433 & 23.0 & $\$ 11.33$ & 6.23 & 310,477 & 321,466 & 492,492 \\
\hline
\end{tabular}

Note. 1 = average attendance; 2 = average absolute change; 3 = average deviation from mean (\%); 4 $=$ average ticket price $(\$) ; 5=$ nonticket price $(\$) ; 6=$ average actual ticket revenue $(\$) ; 7=$ average variable-pricing ticket $(\$) ; 8=$ average variable-pricing ticket and nonticket revenue $(\$)$.

otherwise unreachable because of pricing/income issues, in addition to the aforementioned public-relations benefits.

Currently, teams might not want to implement multiple price points for each game, as shown in Figure 4. As discussed by Levy, Dutta, Bergen, and Venable (1997), menu costs affect the frequency and desire to change prices to reflect changes in demand or supply. Menu costs are costs associated with physically changing prices on products, having to look up prices to tell a customer the price for a particular game, or, more generally, any costs associated with having more than one price for a product or service. In addition, asymmetric information, search costs, and simple confusion for customers regarding the price for different games might cause franchises to have fewer prices for a particular seat throughout the 


\section{Table 8 Summary of Effects of Variable Ticket Pricing (With Capacity Adjustment and Nonticket-Revenue Adjustment), Part 2}

\begin{tabular}{|c|c|c|c|c|c|c|c|}
\hline & 9 & 10 & 11 & 12 & 13 & 14 & 15 \\
\hline Atlanta & $58,689,358$ & $59,328,558$ & 639,200 & 1.1 & $37,864,102$ & $38,489,896$ & 1.7 \\
\hline Baltimore & $75,020,982$ & $75,355,563$ & 334,581 & 0.4 & $48,400,634$ & $48,686,180$ & 0.6 \\
\hline Boston & $55,573,799$ & $56,148,028$ & 574,229 & 1.0 & $35,854,064$ & $36,392,476$ & 1.5 \\
\hline California & $23,816,434$ & $24,298,812$ & 482,378 & 2.0 & $15,365,441$ & $15,847,819$ & 3.1 \\
\hline Chicago (AL) & $37,404,684$ & $38,139,656$ & 734,972 & 2.0 & $24,132,054$ & $24,867,027$ & 3.0 \\
\hline Chicago (NL) & $47,120,107$ & $48,451,267$ & $1,331,160$ & 2.8 & $30,400,069$ & $31,675,750$ & 4.2 \\
\hline Cincinnati & $24,051,406$ & $24,527,936$ & 476,530 & 2.0 & $15,517,036$ & $15,983,459$ & 3.0 \\
\hline Cleveland & $76,534,300$ & $78,775,478$ & $2,241,177$ & 2.9 & $49,376,968$ & $51,228,769$ & 3.8 \\
\hline Colorado & $63,989,693$ & $64,076,289$ & 86,597 & 0.1 & $41,283,673$ & $41,355,136$ & 0.2 \\
\hline Detroit & $19,249,553$ & $20,405,782$ & $1,156,229$ & 6.0 & $12,419,066$ & $13,575,296$ & 9.3 \\
\hline Florida & $28,433,181$ & $28,969,046$ & 535,865 & 1.9 & $18,343,988$ & $18,879,853$ & 2.9 \\
\hline Houston & $32,616,970$ & $33,701,747$ & $1,084,777$ & 3.3 & $21,043,206$ & $22,127,983$ & 5.2 \\
\hline Kansas City & $21,949,610$ & $22,411,903$ & 462,293 & 2.1 & $14,161,039$ & $14,623,331$ & 3.3 \\
\hline Los Angeles & $49,124,509$ & $49,676,206$ & 551,697 & 1.1 & $31,693,231$ & $32,244,929$ & 1.7 \\
\hline Milwaukee & $19,818,383$ & $20,764,351$ & 945,968 & 4.8 & $12,786,054$ & $13,732,021$ & 7.4 \\
\hline Minnesota & $22,871,407$ & $23,716,997$ & 845,590 & 3.7 & $14,755,746$ & $15,601,336$ & 5.7 \\
\hline Montreal & $22,754,708$ & $23,895,483$ & $1,140,776$ & 5.0 & $14,680,457$ & $15,819,930$ & 7.8 \\
\hline New York (AL) & $51,934,362$ & $53,856,573$ & $1,922,211$ & 3.7 & $33,506,040$ & $35,428,250$ & 5.7 \\
\hline New York (NL) & $30,091,356$ & $30,864,393$ & 773,037 & 2.6 & $19,413,778$ & $20,186,815$ & 4.0 \\
\hline Oakland & $20,415,308$ & $21,587,258$ & $1,171,950$ & 5.7 & $13,171,166$ & $14,343,116$ & 8.9 \\
\hline Philadelphia & $31,898,801$ & $32,461,705$ & 562,903 & 1.8 & $20,579,872$ & $21,142,775$ & 2.7 \\
\hline Pittsburgh & $21,584,447$ & $22,561,111$ & 976,664 & 4.5 & $13,925,450$ & $14,902,112$ & 7.0 \\
\hline San Diego & $33,812,057$ & $35,761,936$ & $1,949,879$ & 5.8 & $21,814,230$ & $23,751,402$ & 8.9 \\
\hline San Francisco & $23,375,197$ & $24,946,394$ & $1,571,197$ & 6.7 & $15,080,772$ & $16,651,969$ & 10.4 \\
\hline Seattle & $48,882,717$ & $50,315,365$ & $1,432,648$ & 2.9 & $31,537,236$ & $32,969,885$ & 4.5 \\
\hline St. Louis & $40,948,543$ & $41,625,024$ & 676,481 & 1.7 & $26,418,415$ & $27,078,914$ & 2.5 \\
\hline Texas & $54,223,540$ & $54,875,042$ & 651,502 & 1.2 & $34,982,929$ & $35,634,431$ & 1.9 \\
\hline Toronto & $55,265,885$ & $55,473,682$ & 207,797 & 0.4 & $35,655,410$ & $35,863,207$ & 0.6 \\
\hline Average & $38,980,403$ & $39,891,842$ & 911,439 & 2.8 & $25,148,647$ & $26,038,717$ & 4.3 \\
\hline
\end{tabular}

Note. $9=$ total actual ticket and nonticket revenue $(\$) ; 10=$ total variable-pricing ticket and nonticket revenue (\$); $11=$ total change in ticket and nonticket revenue $(\$) ; 12=$ change in total revenue $(\%) ; 13=$ total actual ticket revenue $(\$) ; 14=$ total variable-pricing ticket revenue $(\$) ; 15=$ change in total ticket revenue $(\%)$.

season than variable pricing predicts. For this reason, many teams have only used a minimal number of ticket-pricing tiers, usually two to four, in their VTP system (Rovell, 2002b).

Confusion and the additional costs associated with changing ticket prices might already be in the process of being eliminated. Kevin Fenton, Colorado Rockies senior director of ticket operations, noted that once the initial confusion regarding multiple price points for games is overcome, patrons realize that tickets can be priced like other industries (Rovell, 2002b). In the near future, the negative fan reaction to changing ticket price will likely be alleviated if not eliminated (Adams, 2003). Ticket offices are also now better equipped to handle menu costs 
issues. Although ticket offices were not prepared to handle extensive VTP in the 1990s, recent technological advances have allowed most American professional sport teams to implement new ticket policies such as bar-coded and print-at-home tickets to prepare for extensive VTP in the future (Zoltak, 2002).

An initial VTP recommendation is that for every $10 \%$ increase in attendance (or specifically, expected attendance) above the average, teams should raise ticket prices by $5 \%$ and receive a gain of $1.2 \%$ in ticket revenue. The practical use of variable pricing, however, would entail creating, at most, five different prices for each seat in a stadium throughout the season, not a different price for each game. High-demand games or series should be priced accordingly, but teams should not forget the potential benefits of lowering prices for less desired games. The present findings reinforce previous research identifying factors such as day of the week or a rivalry game as affecting demand for MLB tickets.

Using the Atlanta Braves again as an example, the average attendance was 35,793 . Based on the variable-pricing ticket prices from Table 5, the recommended pricing schedule for 1996 would have been $\$ 12.00$, \$13.06, and \$15.50. A descriptive analysis of Braves attendance revealed three tiers of games that corresponded with the three price points: games with attendance below 28,831 (greater than -1 standard deviation from the mean), games with an attendance of 28,832 to 42,755 (between 1 and -1 standard deviation from the mean), and games with an attendance over 42,756 (greater than 1 standard deviation from the mean). A factor analysis of games falling within each tier was then performed to finalize the recommended pricing schedule.

For the Braves, a Tier 1 game (average price of \$12.00) would have included games from the second game of the season to May 14, played Sunday through Thursday. Fifteen games would have therefore been classified as Tier 1. A Tier 3 game (average price of $\$ 15.50$ ) would have included all games played on Saturday, opening day, the July 4 game, the final home stand of the season, and games played after May 14 against the Los Angeles Dodgers, a former division rival. Twenty-two games would have fallen into this tier. The remaining 44 games would have been classified as Tier 2, with an average ticket price of $\$ 13.06$, which was the average ticket price for the 1996 season.

The hypothesis that the few teams administering VTP are doing so properly is consistent with the findings. In fact, the present analysis shows that optimal VTP is managed by small changes in ticket prices. The Giants expected to gain an additional \$1 million from VTP in 2002 (Isidore, 2002; Rovell, 2002b). The Giants VTP strategy in 2002 affected only 39 of their 81 home games (all weekend dates). The present analysis shows a gain of about $\$ 1$ million for the 1996 season if optimal pricing were used by the Giants.

In 2002, the Atlanta Braves instituted a VTP strategy for 21 home games-Fridays in May through August and Saturdays throughout the whole season. During these games ticket prices were increased by $\$ 3$, or about $14 \%$. Testing the same policy for the 1996 data, the Atlanta Braves would have 22 home games with VTP using a $9 \%$ increase in price. It is interesting that the Braves' actual policy is more aggressive than the data show for 1996. The St. Louis Cardinals raised prices in 2002 for summer games by $\$ 2$, or $8 \%$. The 1996 data show that an optimal VTP strategy would raise prices by about $9 \%$. 


\section{Directions for Future Research}

There are many areas of inquiry for the future. An analysis of more recent data that include teams using VTP is warranted. The practical application of VTP requires one to be able to accurately forecast the relative attendance of future games. In other words, in order to know which games should have higher prices and which games should have lower prices, team management needs to know whether there is consistency from one season to the next in terms of relative attendance. An interesting behavioral issue is whether the implementation of VTP in earlier games affects the demand for subsequent games.

One factor unaccounted for in this study is the marketing strategies used by organizations in conjunction with VTP price levels. The projected revenue increases identified in this study could potentially be increased substantially by incorporating VTP pricing into teams' marketing plans. Although many MLB teams assign each game or product into VTP levels based on game or product characteristics, little research has investigated how those games of varying characteristics are marketed to different demographic segments of consumers.

In addition, research investigating education and public-relations activities related to VTP should be conducted. Although fans might initially perceive variable pricing as a gauging mechanism, for some fans VTP might allow some expensive games to now become more affordable. Methods to assuage consumer fears and to attract new consumers should be researched. In addition, implementation costs of VTP programs such as menu costs and staff training should be examined and accounted for in future economic examinations of VTP.

Finally, future research should investigate the practical application and public reaction to future variable-pricing systems using technology to change prices by the day, hour, or even minute. Few teams have implemented VTP at this point, believing that widespread use of ticket pricing based completely on supply and demand would not be met with agreement by some consumers (Cameron, 2002). In particular, research should be conducted to identify methods of protecting or enhancing value to season-ticket purchasers when a minute-by-minute VTP policy is implemented.

\section{References}

Adams, R. (2003, January 6). Variable price ticket policy wins converts. Sports Business Journal, p. 14.

Alexander, D.L. (2001). Major League Baseball: Monopoly pricing and profit-maximizing behavior. Journal of Sports Economics, 2, 341-355.

Baade, R., \& Matheson, V. (n.d.). Super Bowl or super (hyper)bole? The economic impact of the Super Bowl on host communities. Unpublished manuscript.

Badenhausen, K., \& Nikolov, C. (1997, June 17). Sports values: More than a game. Financial World, pp. 40-44.

Boyd, D.W., \& Boyd, L.A. (1996). The home field advantage: Implications for the pricing of tickets to professional team sports. Journal of Economics and Finance, 20(2), 23-32.

Brockinton, L. (2003, May 26). New NFL digs offer more revenue possibilities. Sports Business Journal, p. 25.

Bruel, J.S. (2003, January 27). Finding hidden revenue under the seat cushions. Sports Business Journal, p. 23. 
Bruggink, T.H., \& Eaton, J.W. (1996). Rebuilding attendance in Major League Baseball: The demand for individual games. In J. Fizel, E. Gustafson, \& L. Hadley (Eds.), Baseball economics: Current research (pp. 9-31). Westport, CT: Praeger.

Cameron, S. (2002, May 27). Bruins to set prices hourly. Sports Business Journal, pp. 1, 50.

Caple, J. (2001, August 21). All hail ticket scalpers! ESPN Page 2. Retrieved April 16, 2003, from http://espn.go.com/page2/s/caple/010821.html

Coates, D., \& Harrison, T. (2005). Baseball strikes and demand for attendance. Journal of Sports Economics, 6, 282-302.

Demmert, H.G. (1973). The economics of professional team sports. Lexington, MA: Lexington Books.

DeSerpa, A.C. (1994). To err is rational: A theory of excess demand for tickets. Managerial and Decision Economics, 15, 511-518.

Fort, R.D. (2004). Inelastic sports pricing. Managerial and Decision Economics, 25, $87-$ 94.

George, J. (2003, May 26). Phillies go big with entertaining Ashburn Alley. Sports Business Journal, p. 24.

Group commends port authority for variably priced tolls. (2001). Retrieved July 19, 2004, from http://www.tstc.org/press/322_PAtolls.html

Heilmann, R.L., \& Wendling, W.R. (1976). A note on optimum pricing strategies for sports events. In R.E. Machol, S.P. Ladany, \& D.G. Morrison (Eds.), Management Science in Sports (pp. 91-101). New York: North-Holland.

History of ticket scalping. (n.d.). Retrieved July 16, 2004, from http://metg.fateback.com/ metghistory.html

Howard, D.R., \& Crompton, J.L. (2004) Financing sport (2nd ed.). Morgantown, WV: Fitness Information Technologies.

Isidore, C. (2002, December 27). Fans to pay the price(s). CNN/Money. Retrieved July 23, 2004, from http://money.cnn.com/2002/12/27/commentary/column_sportsbiz/ ticket_prices/

King, B. (2002a, April 1). Baseball tries variable pricing. Sports Business Journal, pp. 1, 49.

King, B. (2002b, December 9). MLB varied ticket pricing a boon. Sports Business Journal, p. 23.

King, B. (2003, December 1). More teams catch on to variable ticket pricing. Sports Business Journal, p. 16.

Levy, D., Dutta, S., Bergen, M., \& Venable, R. (1997). The magnitude of menu costs: Direct evidence from large U.S. supermarket chains. Quarterly Journal of Economics, 112, 791-825.

Marburger, D.R. (1997). Optimal ticket pricing for performance goods. Managerial and Decision Economics, 18, 375-381.

McDonald, M., \& Rascher, D.A. (2000). Does bat day make sense?: The effect of promotions on the demand for Major League Baseball. Journal of Sport Management, 14, 8-27.

Noll, R.G. (1974). Government and the sports business. Washington, DC: The Brookings Institution.

O'Keefe, B. (2004, March 29). Pro baseball franchise hit with unusual state audit. Stateline.org. Retrieved July 24, 2004, from www.stateline.org/stateline/ $? \mathrm{pa}=$ story $\&$ sa $=$ showStoryInfo $\&$ print $=1 \& \mathrm{id}=360450$

Pappas, D. (2002). The numbers (part three; part five). Baseball prospectus. Retrieved June 20, 2004, from www.baseballprospectus.com/article.php?articleid=1305

Rascher, D.A. (1999). The optimal distribution of talent in Major League Baseball. In L. Hadley, E. Gustafson, \& J. Fizel (Eds.), Sports economics: Current research (pp. 2745). Westport, CT: Praeger. 
Reese, J.T. (2004). Ticket operations. In U. McMahon-Beattie \& I. Yeoman (Eds.), Sport and leisure operations management (pp. 167-179). London: Continuum.

Riley, D.F. (2002). Ticket pricing: Concepts, methods, practices, and guidelines for performing arts events. Culture Work, 2(6). Retrieved July 19, 2004, from http://aad.uoregon. edu/culturework/culturework20.html

Rishe, P., \& Mondello, M. (2004). Ticket price determination in professional sports: An empirical analysis of the NBA, NFL, NHL, and Major League Baseball. Sport Marketing Quarterly, 13, 104-112.

Rooney, T. (2003, January). The pros and cons of variable ticket pricing. Paper presented at the 2003 National Sports Forum, Pittsburgh, PA.

Rovell, D. (2002a, December 31). Forecasting the sport business future. ESPN.com. Retrieved July 12, 2004, from http://espn.go.com/sportsbusiness/s/2002/1230/1484284.html

Rovell, D. (2002b, June 21). Sports fans feel pinch in seat (prices). ESPN.com. Retrieved July 20, 2004, from http://espn.go.com/sportsbusiness/s/2002/0621/1397693.html

Salant, D. (1992). Price setting in professional team sports. In P. Sommers (Ed.), Diamonds are forever (pp. 77-90). Washington, DC: The Brookings Institution.

Scully, G.W. (1989). The business of Major League Baseball. Chicago: University of Chicago Press.

Travel tips. (2004). Retrieved July 20, 2004, from http://clarkhoward.com/travel/tips/ todays_tip.html

Whitney, J.D. (1988). Winning games versus winning championships: The economics of fan interest and team performance. Economic Inquiry, 26, 703-724.

Zimbalist, A. (2003). May the best team win: Baseball economics and public policy. Washington DC: The Brookings Institution.

Zoltak, J. (2002, July). Tickets and technology: Perfect together. Venues Today, pp. 1, 20.

\section{Appendix}

In order to calculate the new price and quantity in which revenue is maximized $(\eta=-1)$ when the demand curve shifts, refer to Figure 1 at Point $A$ and let

$$
Q_{A}=35,793, P_{A}=\$ 13.06, \text { and set } \eta_{A}=\left(P_{A} / Q_{A}\right) \times\left(\Delta Q_{A} / \Delta P_{A}\right)=-1 \text {. }
$$

At Point $\mathrm{C}$, let

$$
\begin{gathered}
Q_{C}=\left(Q_{A}+Q_{B}\right) / 2=(35,793+48,961) / 2=42,377 \\
P_{C}=\eta_{A} \times Q_{C} \times\left(-P_{A} / Q_{A}\right)=-1 \times 42,377 \times(-\$ 13.06 / 35,793)=\$ 15.46 .
\end{gathered}
$$

The results for the new price and quantity rely on two attributes of linear demand functions. First, the optimal quantity $\left(Q_{C}\right)$ is simply the average of the old quantity $\left(Q_{A}\right)$ and the new actual quantity $\left(Q_{B}\right)$. Second, the new optimal price uses the elasticity formula, $\eta_{C}=\left(P_{C} / Q_{C}\right) \times\left(\Delta Q_{A} / \Delta P_{A}\right)=-1$, and solves for $P_{A}$. A key substitute is to note that $\left(\Delta Q_{A} / \Delta P_{A}\right)=-P_{A} / Q_{A}$, because the inverse of the slope is constant for the old demand and new demand. Also, $P_{A}$ and $Q_{A}$ are given, and $\eta_{A}$ is set equal to -1 . This can be seen in the previous elasticity formula, $\eta_{A}=\left(P_{A} / Q_{A}\right) \times\left(\Delta Q_{A} / \Delta P_{A}\right)=-1$. 